University of Wollongong

Research Online

Faculty of Engineering and Information

Faculty of Engineering and Information

Sciences - Papers: Part B

Sciences

2020

Synthesis and characterization of additive graphene oxide nanoparticles dispersed in water: Experimental and theoretical viscosity prediction of non-Newtonian nanofluid

Yang Xu

Quyen Nguyen

Omid Malekahmadi

Ramin Hadi

Zahra Jokar

See next page for additional authors

Follow this and additional works at: https://ro.uow.edu.au/eispapers1

Part of the Engineering Commons, and the Science and Technology Studies Commons

Research Online is the open access institutional repository for the University of Wollongong. For further information contact the UOW Library: research-pubs@uow.edu.au 


\title{
Synthesis and characterization of additive graphene oxide nanoparticles dispersed in water: Experimental and theoretical viscosity prediction of non- Newtonian nanofluid
}

\author{
Abstract \\ (C) 2020 John Wiley \& Sons, Ltd. Graphene oxide (GO) is a mixture of carbon, oxygen, and hydrogen. GO \\ sheets used to make tough composite materials, thin films, and membranes. GO-water nanofluid's \\ rheological behavior was investigated in this research. Various mass fractions: 1.0, 1.5, 2.0, 2.5, and 3.5 \\ $\mathrm{mg} / \mathrm{ml}$; different temperature ranges: $25^{\circ} \mathrm{C}, 30^{\circ} \mathrm{C}, 35^{\circ} \mathrm{C}, 40^{\circ} \mathrm{C}, 45^{\circ} \mathrm{C}$, and $50^{\circ} \mathrm{C}$; and several shear ranges: \\ $12.23,24.46,36.69,61.15,73.38$, and $122.3 \mathrm{~s}-1$ were studied. X-ray diffraction analysis (XRD), energy \\ dispersive X-ray analysis (EDX), dynamic light scattering analysis (DLS), and Fourier-transform infrared \\ (FTIR) tests studied to analyze phase and structure. Field emission scanning electron microscope \\ (FESEM) and transmission electron microscopy (TEM) tests studied for microstructural observation. The \\ stability of nanofluid was checked by the zeta-potential test. Non-Newtonian behavior of nanofluid, similar \\ to power-law model (with power less than one), revealed by results. Also, results showed that viscosity \\ increased by increment of mass fraction, and on the contrary, increment of temperature, caused a \\ decrease in viscosity. Then, to calculate nanofluid's viscosity, a correlation presented $1.88 \%$ (for RPM $=$ \\ 10 ) and $0.56 \%$ (for RPM $=100$ ) deviation. Finally, to predict nanofluid's viscosity in other mass fractions \\ and temperatures, an artificial neural network has been modeled by R2 $=0.99$. It can be concluded that \\ $\mathrm{GO}$ can be used in thermal systems as stable nanofluid with agreeable viscosity. \\ Disciplines \\ Engineering | Science and Technology Studies

\section{Publication Details} \\ Xu, Y., Nguyen, Q., Malekahmadi, O., Hadi, R., Jokar, Z., Mardani, A., Karimipour, A., Ranjbarzadeh, R., Li, Z. \& \\ Bach, Q. (2020). Synthesis and characterization of additive graphene oxide nanoparticles dispersed in \\ water: Experimental and theoretical viscosity prediction of non-Newtonian nanofluid. Mathematical \\ Methods in the Applied Sciences,

\section{Authors} \\ Yang Xu, Quyen Nguyen, Omid Malekahmadi, Ramin Hadi, Zahra Jokar, Ali Mardani, Arash Karimipour, \\ Ramin Ranjbarzadeh, Zhixiong Li, and Quang Bach
}




\title{
Synthesis and characterization of additive Graphene Oxide nanoparticles dispersed in water: experimental and theoretical viscosity prediction of non-Newtonian nanofluid
}

\author{
Yang Xu' ${ }^{1}$, Quyen Nguyen ${ }^{2}$, Omid Malekahmadi ${ }^{3}$, Ramin Hadi ${ }^{3}$, Zahra Jokar ${ }^{3}$, Ali Mardani ${ }^{3}$, \\ A. Karimipour ${ }^{3}$, Ramin Ranjbarzadeh ${ }^{4}$, Zhixiong Li ${ }^{5,6}$, Quang-Vu Bach*,7 \\ ${ }^{1}$ School of Engineering, Ocean University of China, Qingdao 26100, China. \\ ${ }^{2}$ Institute of Research and Development, Duy Tan University, Danang 550000, Vietnam. \\ ${ }^{3}$ Department of Mechanical Engineering, University of Rome, Sapienza, Italy. \\ ${ }^{4}$ Department of Civil, Constructional and Environmental Engineering, Sapienza University of Rome, Via \\ Eudossiana 18, 00184, Italy. \\ ${ }^{5}$ MJU-BNUT Department-Joint Research Center on Renewable Energy and Sustainable Marine Platforms, \\ Engineering Research Center of Fujian University for Marine Intelligent Ship Equipment, Minjiang University, \\ Fuzhou 350108, China. \\ ${ }^{6}$ School of Mechanical, Materials, Mechatronic and Biomedical Engineering, University of Wollongong, NSW \\ 2522, Australia. \\ ${ }^{7}$ Sustainable Management of Natural Resources and Environment Research Group, Faculty of Environment and \\ Labour Safety, Ton Duc Thang University, Ho Chi Minh City, Vietnam. \\ * Corresponding author at Sustainable Management of Natural Resources and Environment Research Group, \\ Faculty of Environment and Labour Safety, Ton Duc Thang University, 19 Nguyen Huu Tho, Tan Phong Ward, \\ District 7, Ho Chi Minh City, Vietnam; E-mail: bachquangvu@tdtu.edu.vn
}

\begin{abstract}
Graphene Oxide (GO) is a mixture of carbon, oxygen, and hydrogen. GO sheets used to make tough composite materials, thin films and membranes. Graphene Oxide - Water nanofluid's rheological behavior was investigated in this research. Various mass fractions: 1.0, 1.5, 2.0, 2.5, and $3.5 \mathrm{mg} / \mathrm{ml}$; different temperature ranges: $25,30,35,40,45$, and $50^{\circ} \mathrm{C}$; and several shear ranges: 12.23, 24.46, 36.69, 61.15, 73.38, and $122.3 \mathrm{~s}^{-1}$ studied. X-ray diffraction analysis (XRD), Energy dispersive X-ray analysis (EDX), Dynamic light scattering analysis (DLS) and Fourier transform infrared (FTIR) tests, studied to analyze Phase and structure. Field emission scanning electron microscope (FESEM), and Transmission electron microscopy (TEM) tests, studied for Microstructural-observation. The stability of Nanofluid was checked by the Zeta-potential test. Non-Newtonian behavior of nanofluid, similar to power-law model (with power less than one) revealed by results. Also, results showed that viscosity increased by increment of mass fraction, and on the contrary, increment of temperature, cause a decrease in viscosity. Then, to calculate nanofluid's viscosity, a correlation presented which has $1.88 \%$ (for RPM=10) and $0.56 \%$ (for $\mathrm{RPM}=100)$ deviation. Finally, to predict nanofluid's viscosity in other mass fractions and temperatures, an Artificial neural network has been modeled by $R^{2}=0.99$. It can be concluded that $\mathrm{GO}$, can be used in thermal systems as stable nanofluid with agreeable viscosity.
\end{abstract}


Keywords: Graphene Oxide; Rheological behavior; Viscosity; Correlation; ANN

\begin{tabular}{|c|c|c|c|}
\hline \multicolumn{2}{|c|}{ Nomenclature } & \multicolumn{2}{|c|}{ Subscripts } \\
\hline DLS & dynamic light scattering & bf & Base Fluid \\
\hline GO & Graphene Oxide & Exp & Experimental \\
\hline m & Consistency index $\left(\right.$ Pa.s $\left.^{\mathrm{n}}\right)$ & $\mathbf{n f}$ & Nanofluid \\
\hline n & Power law index & np & Nanoparticle \\
\hline RPM & Round per minute & pred & Predicted \\
\hline TEM & transmission electron microscopy & & \\
\hline Vis & Viscosity & & \\
\hline XRD & X-ray diffraction & & \\
\hline ZP & Zeta potential & & \\
\hline
\end{tabular}

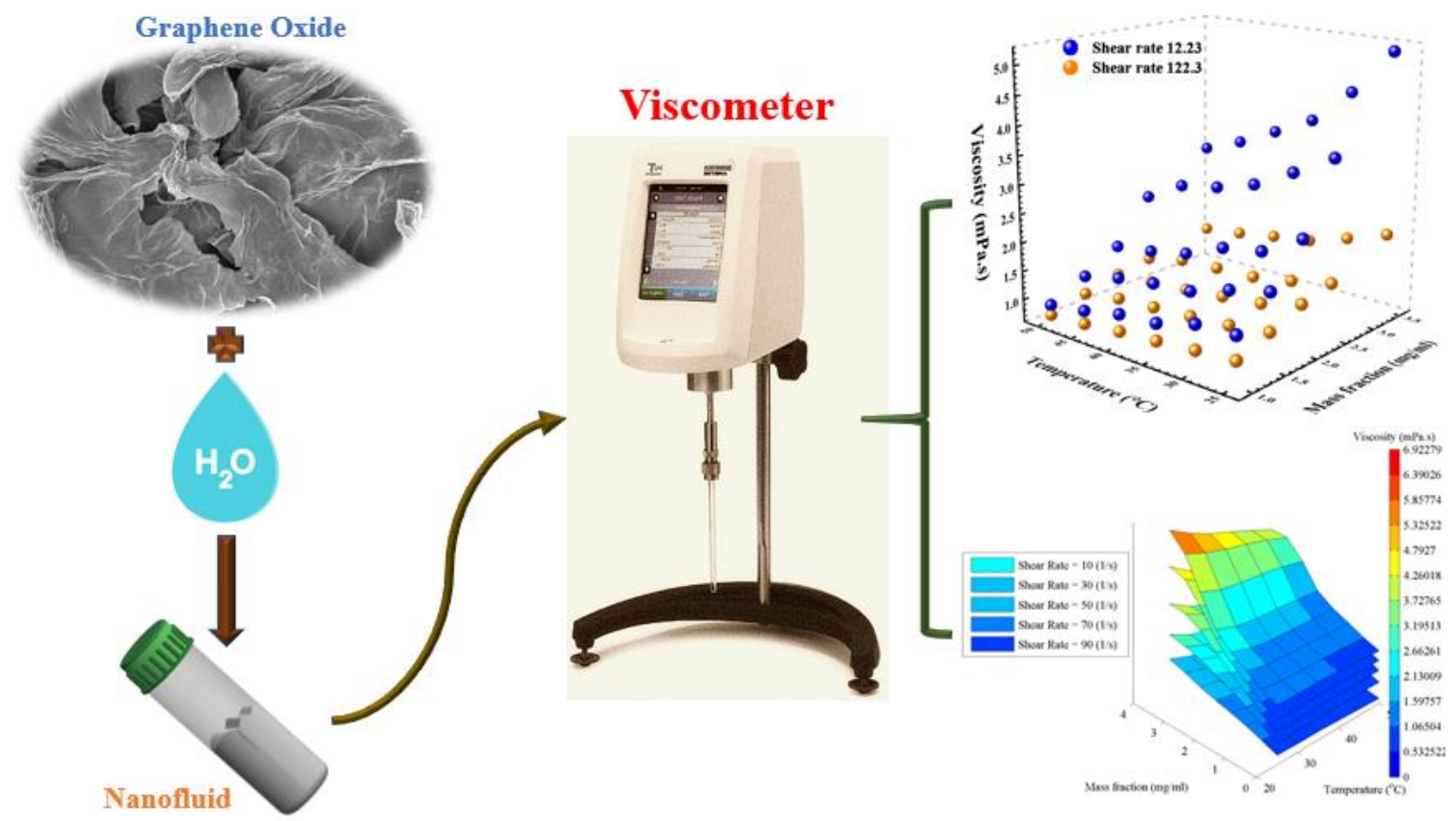

Graphical Abstract 


\section{Introduction}

Graphene Oxide (GO), has a two-dimensional structure with superb mechanical and thermal properties [1]. Despite its excellent properties, GO mass-production at a low cost is important. Also, the production method must be eco-friendly due to its usage in biocomposites and biofilms [2]. Indeed, in nature, we can find Graphene sheets; however, the purity is another requirement to produce Graphene Oxide [3]. Production of Graphene from Graphite can be done physically and chemically. For this purpose, the selection of graphite is important and thus, Flake graphite with size less than one mm is required [4]. For useful applications, Graphene Oxide can also be selfassembled or fabricated in macroscopic microstructures and compositions [5]. In the Staudenmaier method (that needs four days), about two-thirds of fuming $\mathrm{HNO}_{3}$ with concentrated $\mathrm{H}_{2} \mathrm{SO}_{4}$ replaced and $\mathrm{KClO}_{3}$ added in multiple portions which allow the reaction in a vessel. Then, a new method introduced by hummers and Offeman (H method) in 1958. This method is widely accepted to synthesis GO and has some advantages. First, its production time reduced to hours instead of days; then, reaction safety increased by adding $\mathrm{KMnO}_{4}$ instead of $\mathrm{KClO}_{3}$, and finally, acid fog eliminated by adding $\mathrm{NaNO}_{3}$ instead of $\mathrm{HNO}_{3}$ [6]. Tour and co-workers improved this method (MH method) by excluding $\mathrm{NaNO}_{3}$ and adding more $\mathrm{KMnO}_{4}$ [7]. Also, by using an improved Hummers method, Graphene Oxide can be produced without using $\mathrm{NaNO}_{3}$ which causes more low cost and more eco-friendly effects [8].

In the oil, gas and petrochemical industries, heat exchangers play a major role and thus, more research to improve their efficiency is required. Using nanofluids by different types of nanomaterials and basefluid are recent studies in this field [9]. Due to its important usage in industries, nanofluids should be tested more to understand their properties and their effects. Thermal conductivity, Thermal stability and Viscosity are important properties of a nanofluid [10]. Despite numerous studies in thermal conductivity, limited studies exist on viscosity properties. Totally, Nanofluid is a suspension of particles or tubes with more thermal properties compared to base fluid. Research trends for nanofluid and their properties show global motivation in characterization and usage of nanofluids to gain more advantages. Nanoparticle properties such as shape, size, and also an interaction between nanoparticles and base fluid effects properties [11]. Rheological behavior and aggregate size of nanofluid are related to each other. A nanofluid can show both Newtonian and non-Newtonian behavior. Nanofluid behavior is due to its shape, size and mass fraction. 
Many studies conducted to realize properties of nanofluids containing carbon-based materials, such as Graphene, Graphene Oxide and MWCNT [12]. Adding more of carbon-based materials to base fluid, create a gel-like fluid and thus, nanofluid viscosity increase which is undesirable [13]. Due to the unique physicochemical properties of graphene-based materials, and also their compatibility with other compounds, more experiment studies are required. There are few types of research about the effect of particle size and viscosity of graphene oxide nanofluids [14, 46-63].

In this paper, Graphene Oxide synthesized via the $\mathrm{MH}$ method. After that, Graphene Oxide added to Water and nanofluid prepared at mass fractions 1.0 to $3.5 \mathrm{mg} / \mathrm{ml}$. Then, experiments were done at various temperatures. By curve fitting method, a new correlation presented to calculate the viscosity of Graphene Oxide/Water nanofluid. Finally, artificial neural network modeled data.

\section{Materials and Methods}

\subsection{Materials}

With respect to KPA-Iran, Flake graphite (FG) prepared with excellent purity. Also, other materials used in order to synthesis, had excellent purity with analytical grade. Figure 1 shows the Graphene Oxide and Flake Graphite 3D-schematic form. Also, Properties of nanomaterial and basefluid are presented in Table 1.

Table 1. Thermophysical Properties of Base Fluid and Nanoparticle

\begin{tabular}{|cccc|}
\hline Properties & Water (Base fluid) & Flake Graphite & $\begin{array}{c}\text { Graphene Oxide } \\
\text { (Nanoparticle) }\end{array}$ \\
\hline Chemical formula & $\mathrm{H}_{2} \mathrm{O}$ & $\mathrm{C}$ & $\mathrm{C}$ \\
Molar mass $(\mathrm{g} / \mathrm{mol})$ & 18.0153 & 12.01 & 12.01 \\
Density $\left(\mathrm{gr} / \mathrm{m}^{3}\right)$ & $\sim 1.0$ & $\sim 2.0$ & $\sim 2.3$ \\
Viscosity $(\mathrm{mPa} . \mathrm{s})$ & --- & --- & This paper \\
\hline
\end{tabular}




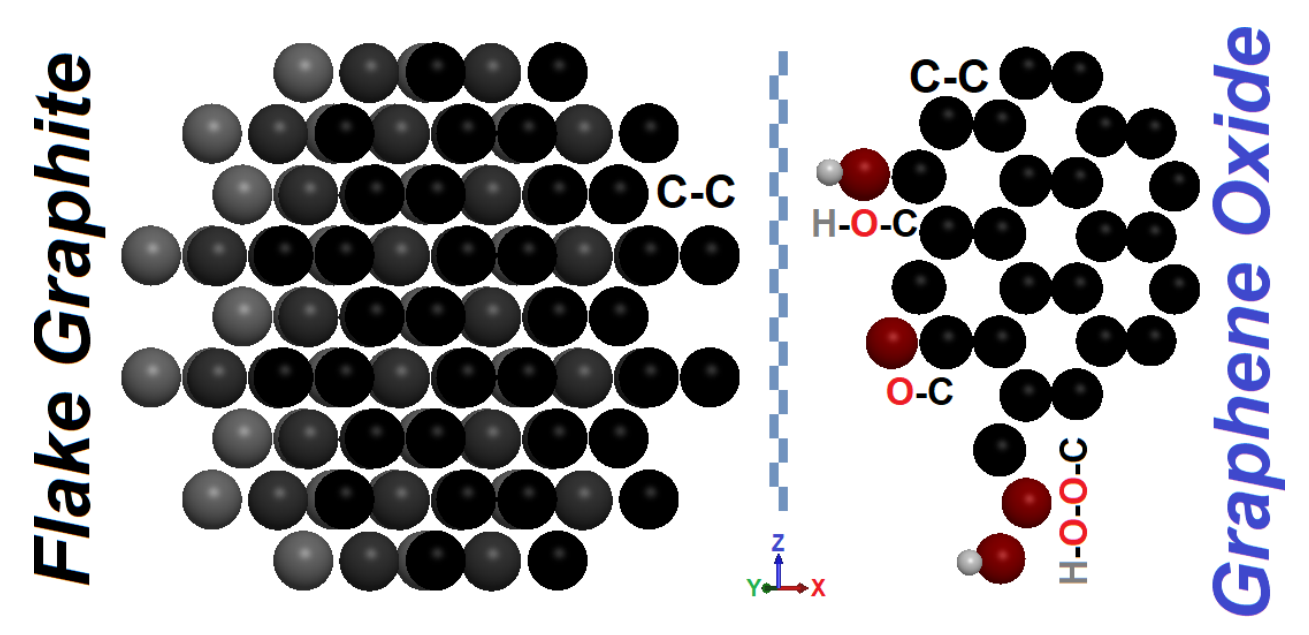

Figure 1. Graphene Oxide and Flake Graphite 3D-schematic form

\subsection{Powder Synthesis \& Nanofluid Preparation}

Figure 2. displays synthesis and preparation steps of Graphene Oxide (GO) powder and nanofluid. XRD tested by a D8ADVANCE Bruker X-ray diffractometer. EDX used to confirm XRD results. Also, DLS was measured by VASCO Cordouan Technologies. Then, FTIR spectra was recorded on JASCO 6300JAPAN. Also, FESEM applied to observe sample morphology by NOVA NanoSEM [15].

The first step before thermophysical properties measuring, is the preparation of nanofluid. By adding GO to deionized Water, nanofluid prepared at concentration of 1.0, 1.5, 2.0, 2.5, and 3.5 $\mathrm{mg} / \mathrm{ml}$. The total concentration of GO used in nanofluid can be computed from Equation (01). GO mass was measured by digital A\&D GF-600 Weighing Lab Balance with 1-mg precision. To prepare the nanofluid, a two-stage method because of its reasonable cost and simplicity was used. In this technique, synthesized material, dispersed in water base fluid by applicable dispersion approach. However, the biggest problem in this method, is agglomeration. To prevent this, and to obtain a good dispersion, $\mathrm{pH}$ meter, magnetic stirring (for $100 \mathrm{~min}$ ), and sonication (for $20 \mathrm{~min}$ ) with ultrasonic processor $400 \mathrm{~W}-24 \mathrm{kHz}$ (Hielscher Company, Germany) is used. Thus, a stable suspension prepared [16]. 


$$
\phi=\left[\frac{\left(\frac{w}{\rho}\right)_{G O}}{\left(\frac{w}{\rho}\right)_{G O}+\left(\frac{w}{\rho}\right)_{\text {Water }}}\right] * 100
$$

Where $\varphi$ is mass fraction percentage, $\mathrm{m}$ indicates mass and $\rho$ is density.
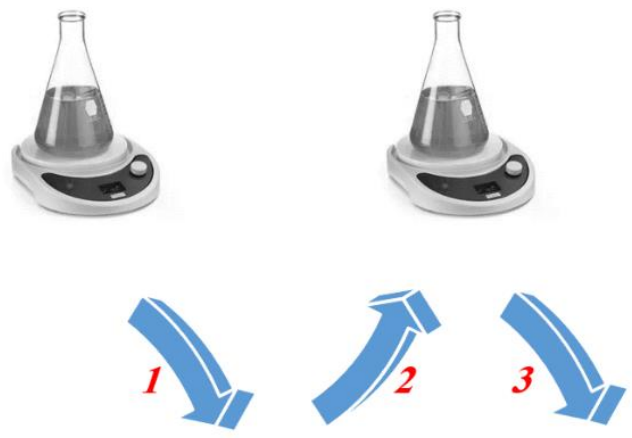

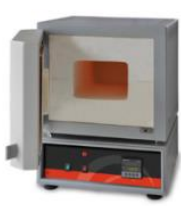$$
4=>5
$$

The filtrate is heated

in a muffle furnace at

$60^{\circ} \mathrm{C}$ and allowed to

cool overnight in air

$5 \Rightarrow 6$

The filtrate is

sonicated in $\mathrm{H}_{2} \mathrm{O}_{2}$

$$
6 \Rightarrow 7
$$

The yellow brown powder is washed with warm water to

remove impurities and finally

dried at $60^{\circ} \mathrm{C}$ to get $\mathrm{GO}$

$7=>8$

After

complete drying, GO with different mass fraction added to

deionized water

$$
\text { Final Step }
$$

To break agglomeration, ultrasonic used

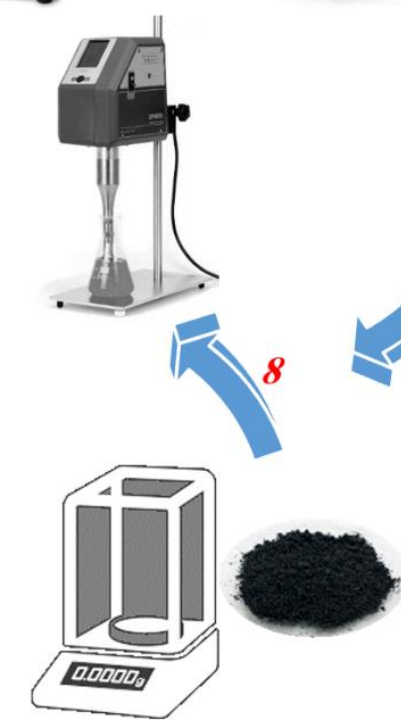

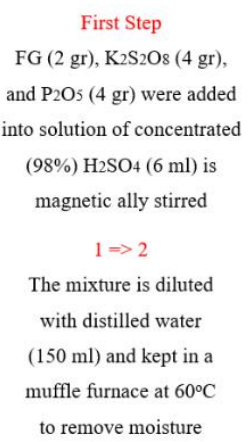

to remove moisture

$2=>3$

A solution of pre-oxidised graphite powder

(1 gr), $\mathrm{H} 2 \mathrm{SO} 4(46 \mathrm{ml})$, $\mathrm{KMnO} 4(6 \mathrm{gr})$ and

NaNO3 ( $1 \mathrm{gr})$ is prepared and the solution

stirred. distilled water $(280 \mathrm{ml})$ and $(30 \%)$ $\mathrm{H} 2 \mathrm{O} 2(5 \mathrm{ml})$ is finally

stirred. The filtrate

obtained is washed with HCL $(10 \%)$

$$
3=>4
$$

The brown filtrate

after being washed with $\mathrm{HCL}(10 \%)$
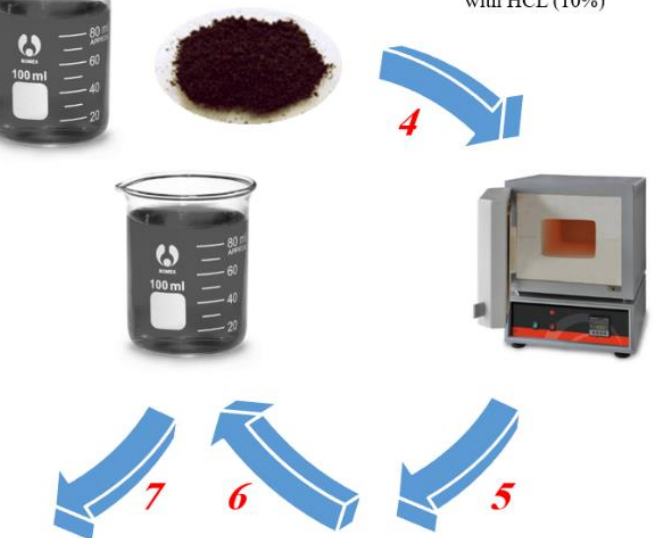

5

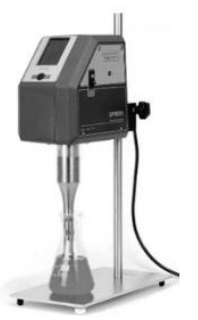

Figure 2. Schematic diagram of powder synthesis steps (Flake Graphite to Graphene Oxide) and also nanofluid preparation

\subsection{Viscosity Measurement}

To measure GO-Water viscosity, a DV2EXTRAPro rotational viscometer (BROOKFIELD) with 
5\% error is applied [17]. These viscometers work based on measuring the resistance of the fluid due to the torque created by the spindle that is immersed in the fluid. Further, an precise temperature bath (LAUDA Alpha RA 8) was connected to viscometer to provide temperature stability and also measure the effects of temperature on viscosity of the nanofluid. as a result, it is possible to analyse the viscosity and rheological behavior of nanofluids under the influence of shear rate and temperature at various concentrations. To measure the viscosity of GO-Water, ULA spindle (1-200 RPM/ 1-6 mPa.S with 1.223 shear rate coefficient and a small sample adapter system) is used [18]. Earlier, DV2T was calibrated at room temperature by experiments with distilled water and its data compare with accessible viscosity data for pure water [19]. Viscosity analysis at different shear rates, studied four times for $25,30,35,40,45$ and $50^{\circ} \mathrm{C}$ temperature, independently. The accuracy and repeatability of the viscometer used are $\pm 0.2 \%$ and $\pm 1 \%$ in the full-scale range (FSR) of measurements, accordingly. To calculate FSR through Equation (02), the values of torque coefficient (TK), spindle multiplier constant (SMC) and rotational speed of spindle by means of device round per minute (RPM) are needed.

$$
\operatorname{FSR}(\mathrm{mPa} . \mathrm{s})=T K * S M C * \frac{10000}{R P M}
$$

The values of TK and SMC for ULA spindle are 0.0937 and 0.64 , accordingly. Thus, the repeatability of the results can be computed from Equation (03).

Repeatability $(\mathrm{mPa} . \mathrm{s})=0.002(F S R)$

The measurement error for the viscosity of nanofluids in this research can be computed by the Equation (04), in accordance with the user's manual of viscometer.

$\operatorname{Error}(m P a . s)=0.01(F S R+\mu)$

In which, $\mu(\mathrm{mPa} . \mathrm{s})$ represents the nanofluids viscosity.

\section{Result}

\subsection{Synthesis}

\subsubsection{Phase Investigation}

$X R D$

Figure 3 displays XRD pattern and crystallinity structure of synthesized GO by MH method. The 
sharp (001) peak can be seen at $2 \theta=10.775^{\circ}$, corresponding to the d-spacing of $8.214 \AA$ Á. However, this sharp (002) peak in FG, can be seen at $2 \theta=26.475^{\circ}$ corresponding to the d-spacing of 3.363 $\AA ̊$ by Bragg's law $\left(1.541^{\circ} \AA\right.$ \& wavelength of $\left.\mathrm{Cu} \mathrm{K \alpha}\right)$. This means, in the synthesizing process, the crystal plane changed from (002) to (001) which can be seen at 20; Also, d-spacing increased about $4.851 \AA ̊$ [20].

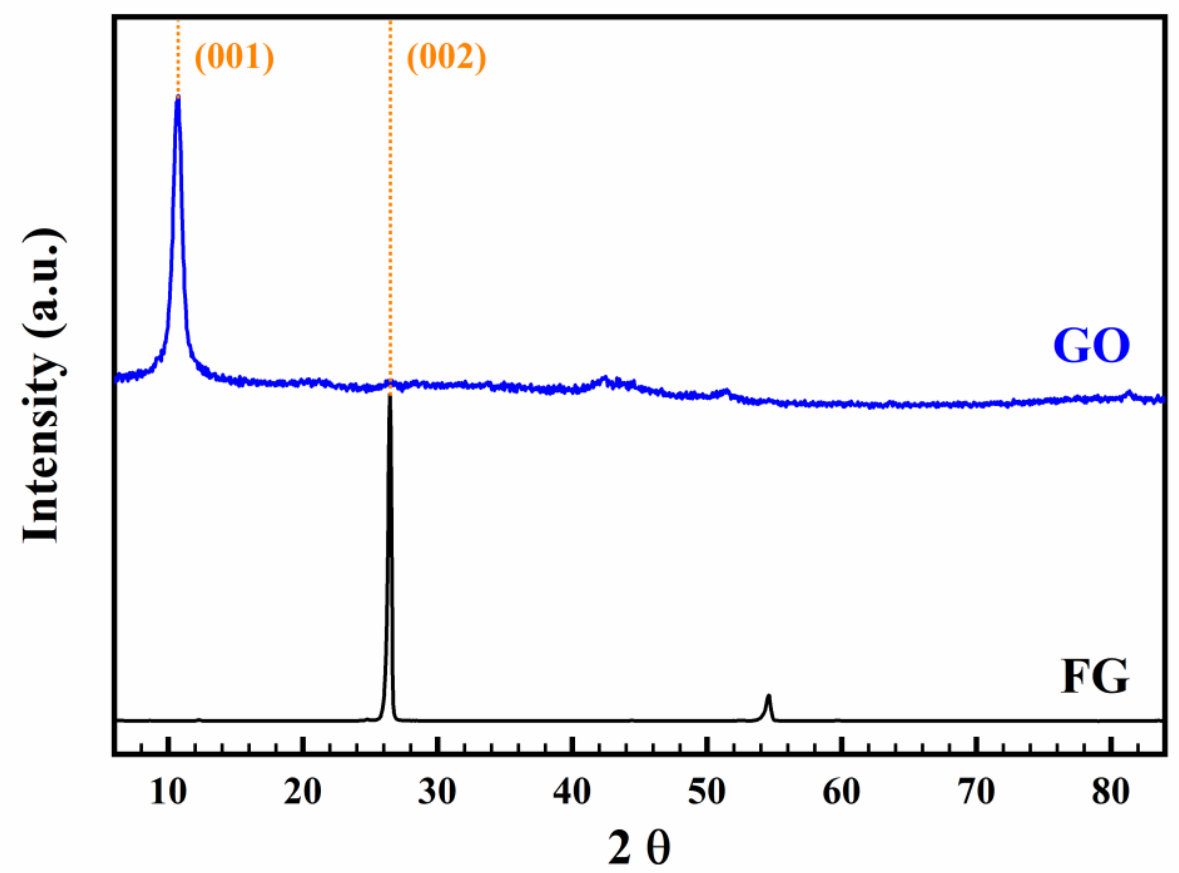

Figure 3. XRD comparison between Graphene Oxide (GO) and Graphite (FG)

\section{$D L S$}

DLS used to determine size distribution for FG and GO dispersed in Water. GO has a 2D structure which means only one dimension is at the nanoscale. However, DLS cannot measure the thickness itself, and the size of two other dimensions (which are in microscale) also shown in Figure. Figure 4 shows that GO (About 69.4 vol.\% has $474.28 \mathrm{~nm}$ ) has less volume than Flake Graphite (Around 39.5 vol.\% has $653.49 \mathrm{~nm})[21]$. 


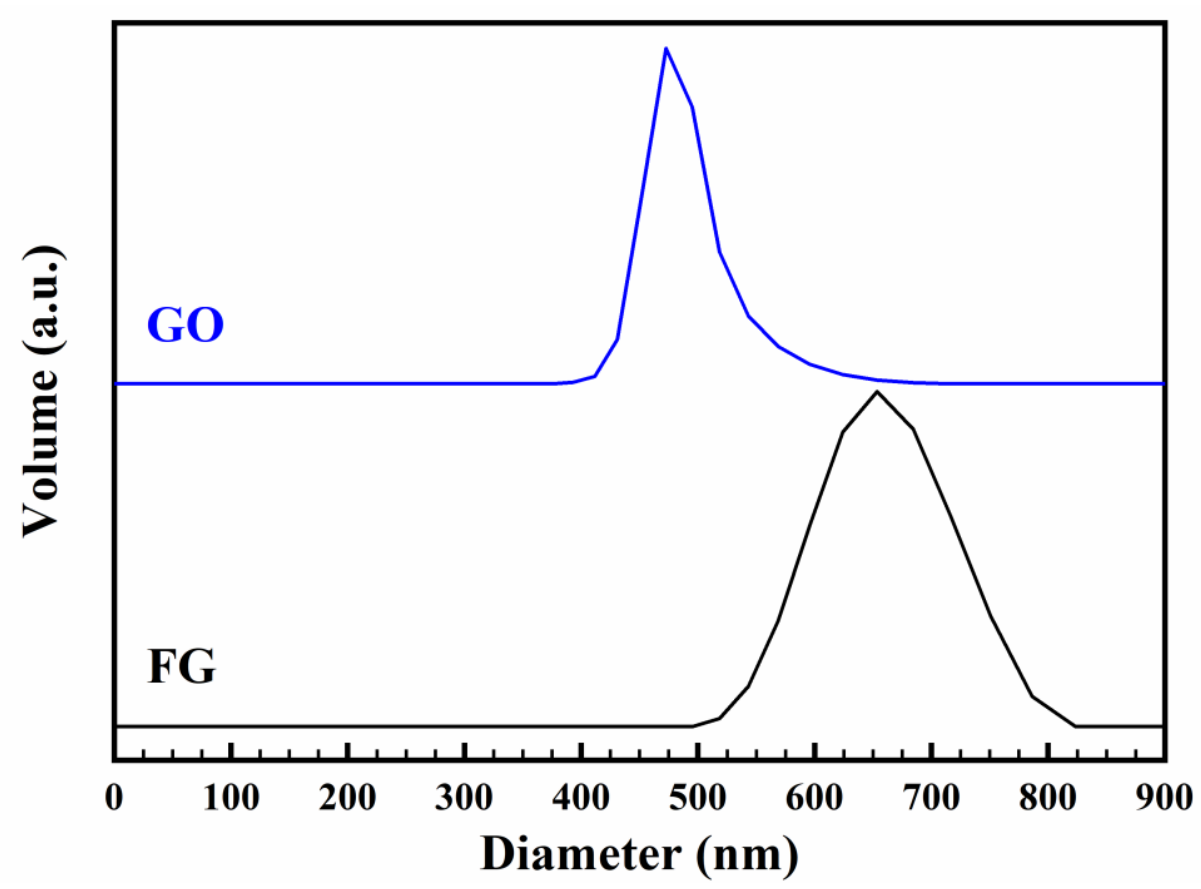

Figure 4. DLS comparison between Graphene Oxide (GO) and Graphite (FG)

\section{FTIR}

Figure 5 shows FTIR spectroscopy analysis. To study structure and functional groups of Flake Graphite and Graphene Oxide, FTIR used. For GO sample, the wide peak from 2859.3 to 3720.82 $\mathrm{cm}^{-1}$, which correspond to $\mathrm{OH}$ groups of water molecules reported in the high-frequency area. Graphene Oxide hydrophilicity can be concluded from this wide peak. carboxyl $\mathrm{C}=\mathrm{O}$ characteristic peaks of Graphene Oxide, reported in $1738.51 \mathrm{~cm}^{-1}$. To compare both FG and GO, Figure 5 displays a lower intensity of FG peaks. As a report, functional groups can be seen as:

$\mathrm{O}-\mathrm{H}, \mathrm{C}=\mathrm{C}, \mathrm{C}-\mathrm{OH}$ and $\mathrm{C}-\mathrm{O}$ at $3420.14 \mathrm{~cm}^{-1}, 1622.8 \mathrm{~cm}^{-1}, 1224.47 \mathrm{~cm}^{-1}, 1052.94 \mathrm{~cm}^{-1}$, for Graphene Oxide respectively and also $\mathrm{C}=\mathrm{C}$, and $\mathrm{C}-\mathrm{O}$ at $1578.01 \mathrm{~cm}^{-1}$ and $1028.32 \mathrm{~cm}^{-1}$ for Flake Graphite respectively [22]. 


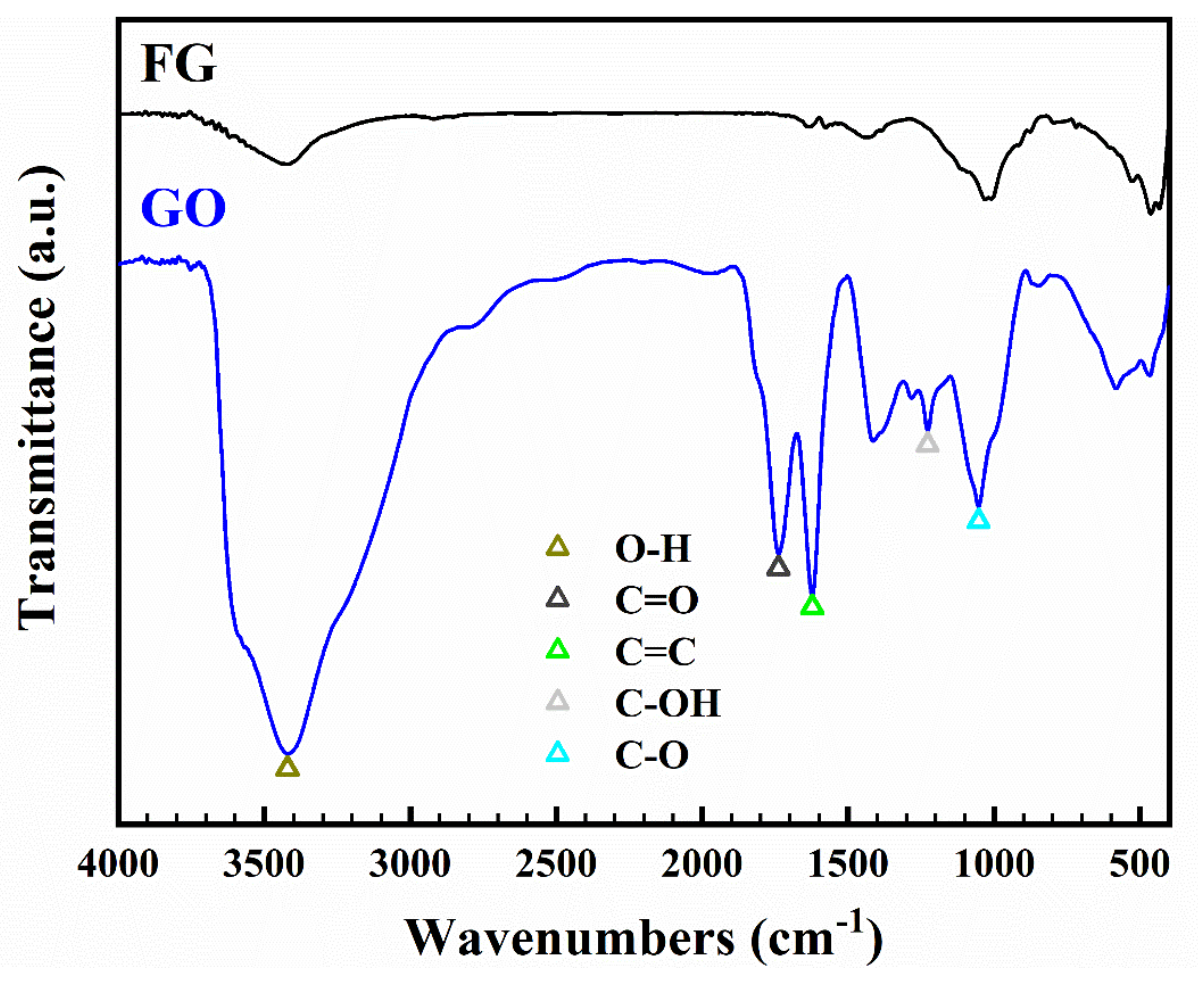

Figure 5. FTIR comparison between Graphene Oxide (GO) and Graphite (FG)

\subsubsection{Microstructural Observations}

\section{FESEM and EDX}

Figure 6 displays the FESEM of the disordered and amorphous 2D structure of synthesized GO. It can be seen that GO has a layer structure and its thickness is less than 100nm. The thick structure of GO is because of covalently bound oxygen presence, and it is easy to determine sheets edges. Wrinkled areas are one above the other. GO sheets have 1 - $3 \mu \mathrm{m}$ flake diameter [23]. EDX test done for 2 points for FG and GO. Figure 7, displays that Flake graphite have around 82.05 at.\% C, 14.82 at.\% $\mathrm{O}$ and 3.13 at.\% $\mathrm{N}+\mathrm{Fe}+\mathrm{Si}+\mathrm{Al}$. However, Graphene Oxide has more purity and have around 61.12 at.\% C, 37.94 at.\% $\mathrm{O}$ and 0.94 at.\% S. 

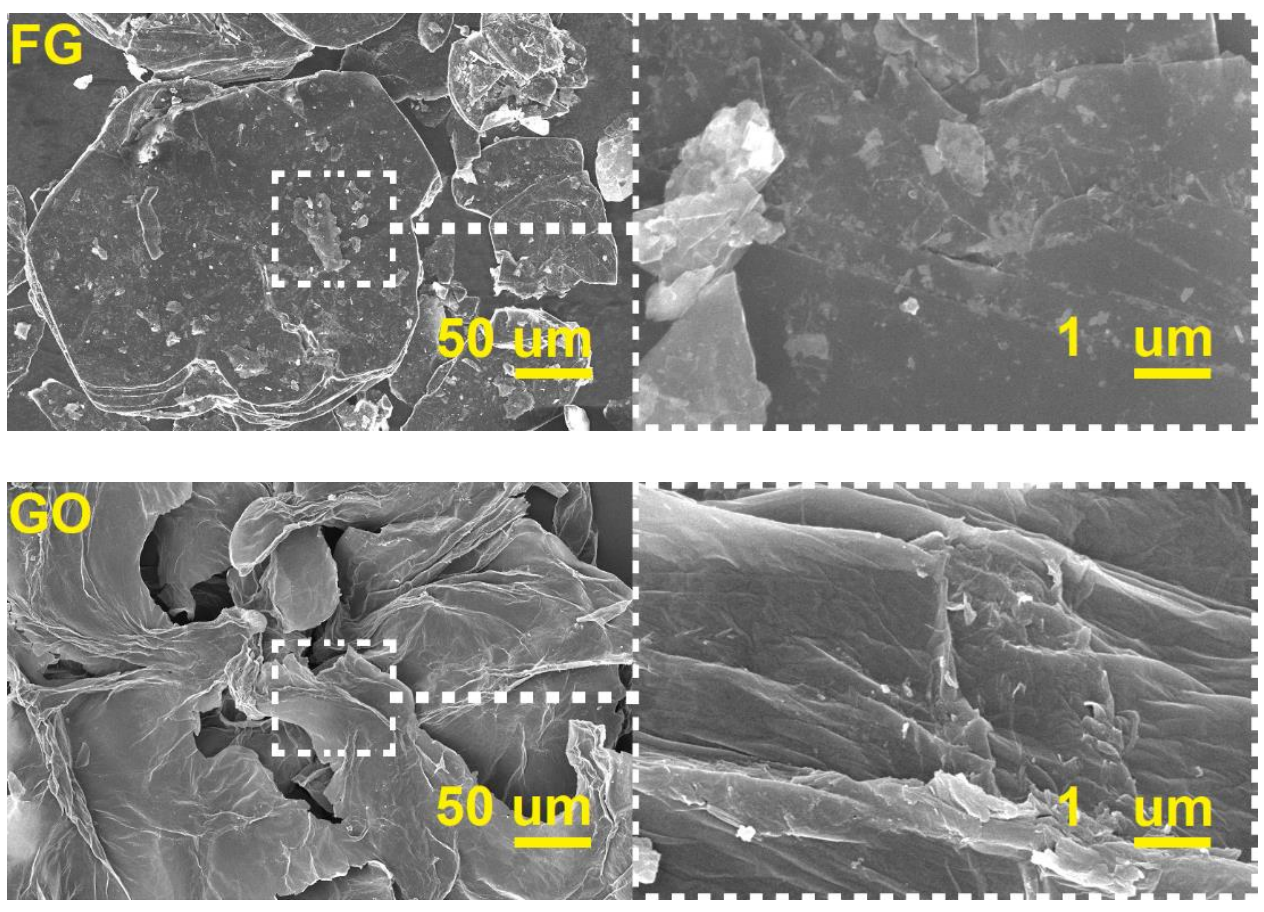

Figure 6. FESEM of Graphene Oxide (GO) and Graphite (FG)
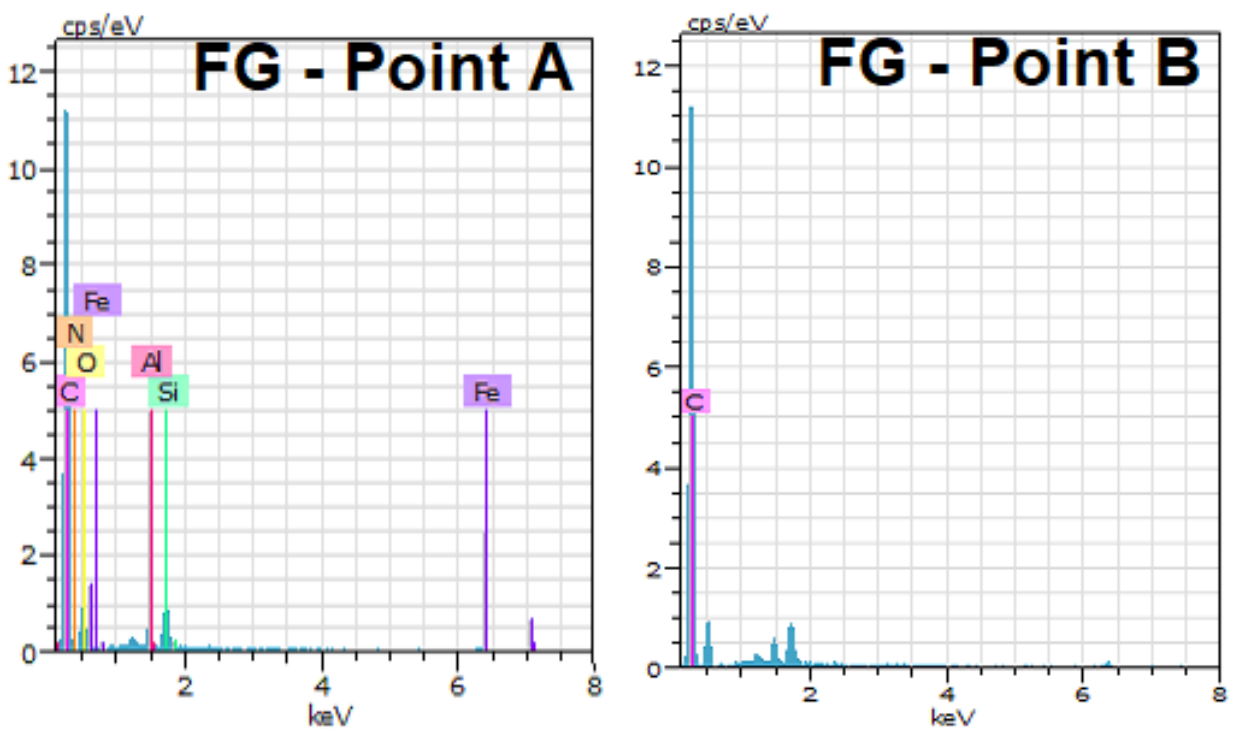

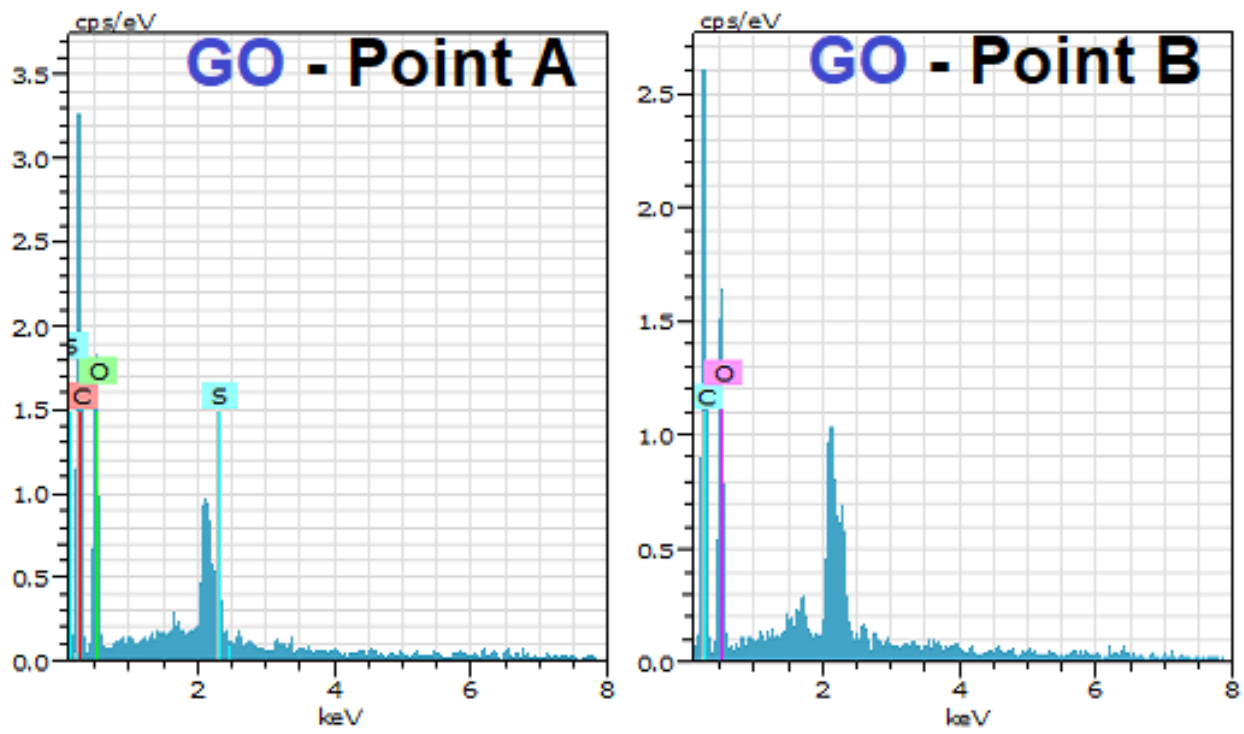

Figure 7. EDX of Graphene Oxide (GO) and Graphite (FG)

Table 2. EDX pattern

\begin{tabular}{|c|c|c|c|c|c|c|c|c|c|}
\hline \multicolumn{5}{|c|}{ First Point of Flake Graphite } & \multicolumn{5}{|c|}{ First Point of Graphene Oxide } \\
\hline \multicolumn{5}{|c|}{ El AN Series unn. C norm. C Atom. C Error (1 Sigma) } & \multicolumn{5}{|c|}{ El AN Series unn. C norm. C Atom. C Error (1 Sigma) } \\
\hline & {$[w t . \%]$} & [wt.\%] & [at.\%] & [wt.\%] & & [wt.\%] & [wt.\%] & [at.\%] & [wt.\%] \\
\hline $\mathrm{C}$ & 76.42 & 76.42 & 82.05 & 12.88 & $\mathrm{C}$ & 53.54 & 53.54 & 61.12 & 11.86 \\
\hline $\mathrm{O}$ & 18.39 & 18.39 & 14.82 & 5.94 & $\mathrm{O}$ & 44.27 & 44.27 & 37.94 & 11.34 \\
\hline $\mathrm{N}$ & 2.05 & 2.05 & 1.89 & 2.55 & S & 2.19 & 2.19 & 0.94 & 0.19 \\
\hline $\mathrm{Si}$ & 1.42 & 1.42 & 0.65 & 0.14 & & & & & \\
\hline $\mathrm{Fe}$ & 0.98 & 0.98 & 0.24 & 0.16 & & & & & \\
\hline $\mathrm{Al}$ & 0.74 & 0.74 & 0.35 & 0.10 & & & & & \\
\hline Total & 100 & 100 & 100 & & & 100 & 100 & 100 & \\
\hline \multicolumn{5}{|c|}{ Second Point of Flake Graphite } & \multicolumn{5}{|c|}{ Second Point of Graphene Oxide } \\
\hline \multicolumn{5}{|c|}{ El AN Series unn. C norm. C Atom. C Error (1 Sigma) } & \multicolumn{5}{|c|}{ El AN Series unn. C norm. C Atom. C Error (1 Sigma) } \\
\hline & [wt.\%] & [wt.\%] & [at.\%] & [wt.\%] & & [wt.\%] & [wt.\%] & [at.\%] & [wt.\%] \\
\hline \multirow[t]{2}{*}{$\mathrm{C}$} & 100.00 & 100.00 & 100.00 & 16.86 & $\mathrm{C}$ & 50.14 & 50.14 & 43.02 & 12.17 \\
\hline & & & & & $\mathrm{O}$ & 49.86 & 49.86 & 56.98 & 10.88 \\
\hline Total & 100 & 100 & 100 & & & 100 & 100 & 100 & \\
\hline
\end{tabular}

TEM

Transmission electron microscopy used to confirm that GO thickness is under 100nm. In the TEM technique, to make an image, a beam of electrons transmitted through a specimen. It can be seen in Figure 8 that Graphene Oxide has a 2D layer structure and its thickness is less than 50nm [24]. 


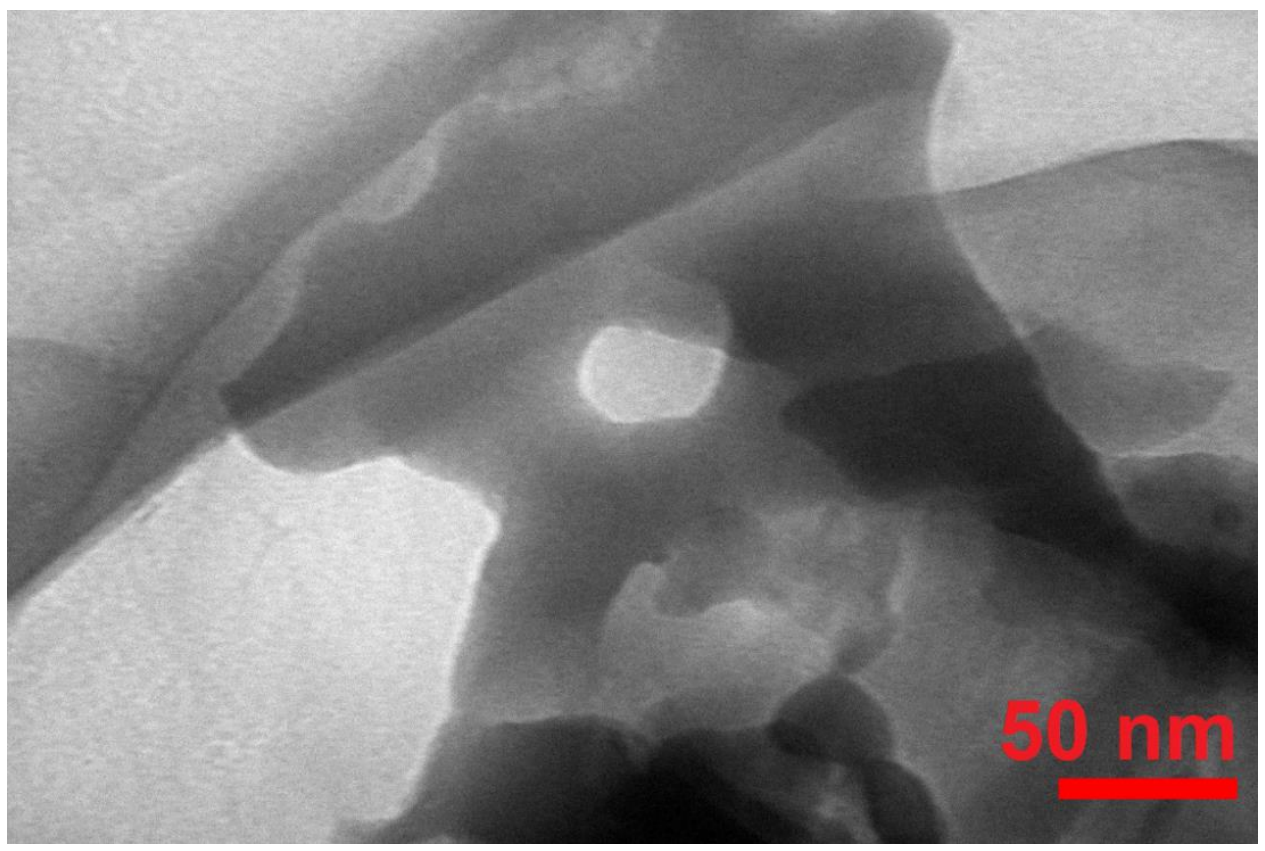

Figure 8. TEM of Graphene Oxide (GO)

\subsection{Generate the Nanofluid}

\subsubsection{Stability}

\section{Zeta Potential}

Figure 9 displays the zeta potential of Graphene Oxide at 1.0 and $4.5 \mathrm{mg} / \mathrm{ml}$. GO colloid solution at a $\mathrm{pH}$ range of $2-4$, displays negative zeta potential. As reported by ASTM, ZP ranges of 20 to $30 \mathrm{mV}$ are moderately stable and $> \pm 30 \mathrm{mV}$ are highly stable. ZP for mass fractions 1.0 and 4.5 are $36 \mathrm{mV} 38.3 \mathrm{mV}$, respectively, these $\mathrm{ZP}$ values, displays high stability of nanomaterial in the aqueous phase. By these ZP values, it can be concluded that GO has aggregation behavior by increasing the mass fraction. By increasing mass fraction, GO negative electrical surface charge, rose which is due to the ionization of carboxylic acid groups [25]. This trend was not seen through the previous works [64-79]. 


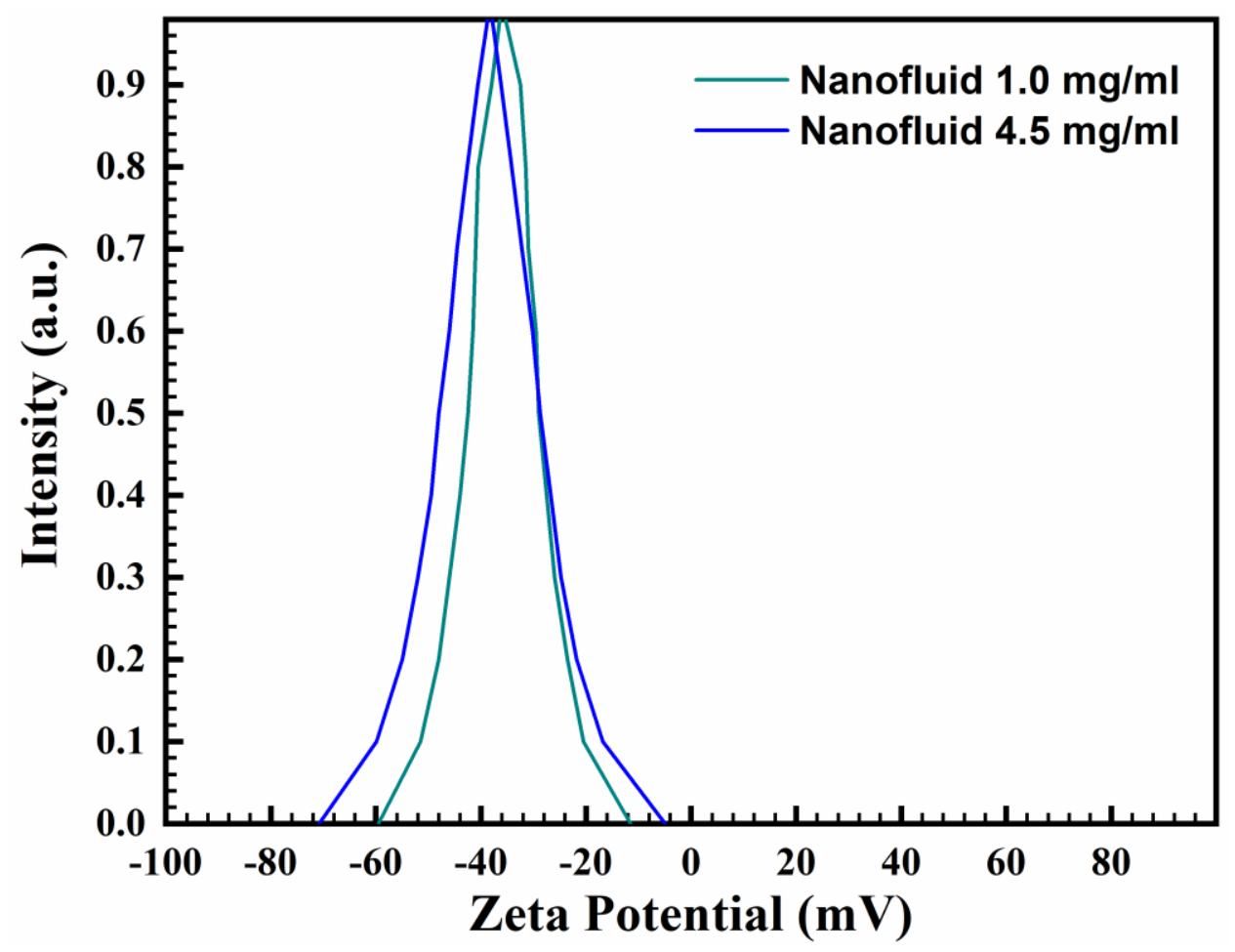

Figure 9. Zeta potential of Graphene Oxide (concentration of $1.0 \mathrm{mg} / \mathrm{ml} \& 4.5 \mathrm{mg} / \mathrm{ml}$ )

\subsubsection{Viscosity}

\section{Validation}

First, to confirm viscometer accuracy, DV2T viscometer validity was specified by distilled water (as calibration fluid) and compared to the ASHRAE handbook [26]. The error of device measurement was acceptable (less than $5 \%$ ) at $\mathrm{T}=25^{\circ} \mathrm{C}$ (regarding its manual). Figure 10, shows maximum error of $4.58 \%$ (at $\mathrm{T}=25^{\circ} \mathrm{C}$ ). 


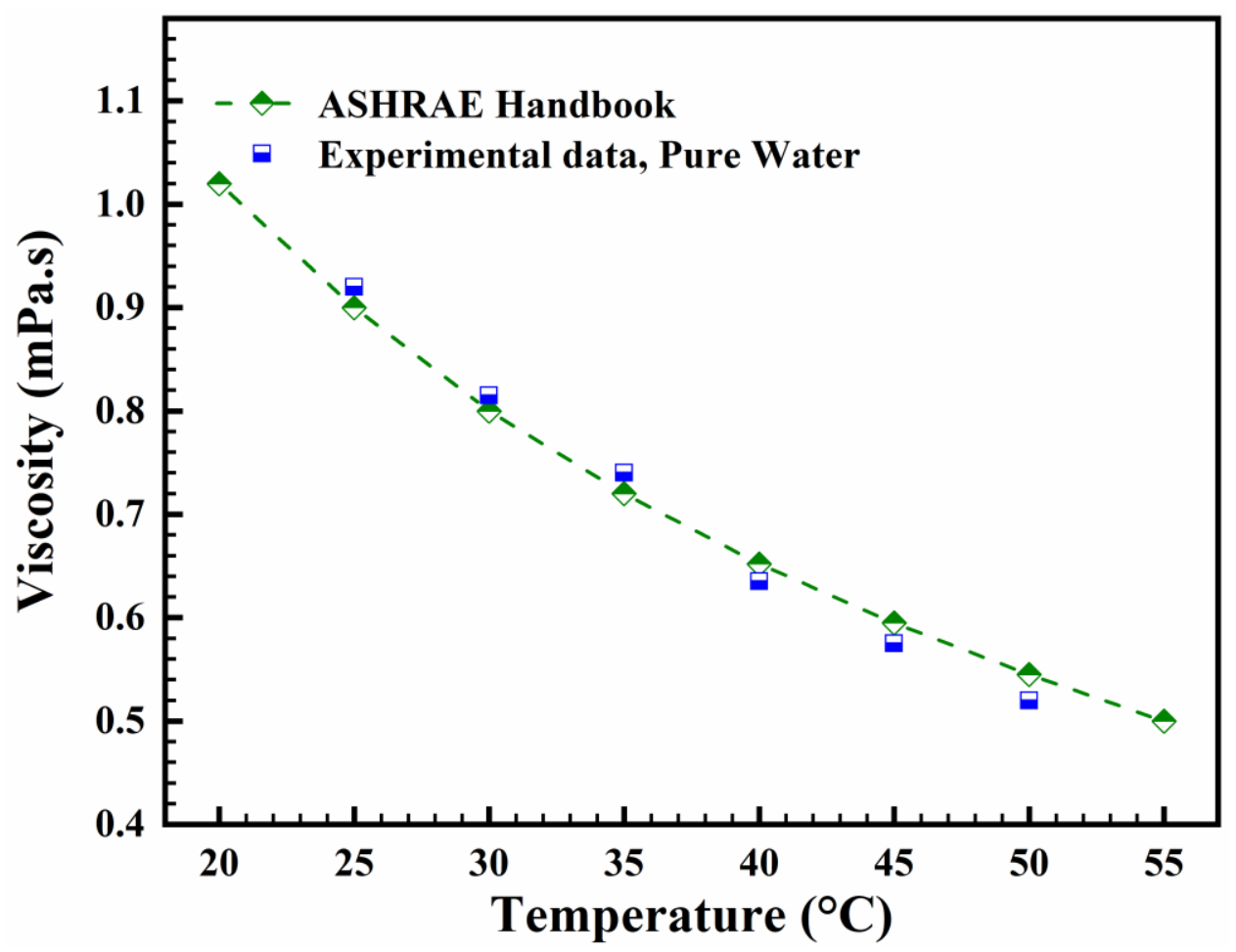

Figure 10. Viscosity of experimental data for pure water versus ASHRAE handbook [26] data by temperature

\section{Mass Fraction and Temperature Effect}

Determining nanofluid's rheological behavior whether it shows Newtonian or non-Newtonian behaviors at various mass fractions and temperatures is important [27]. Figure 11 shows viscosity by mass fraction at various temperatures in shear rates of 12.23 and 122.3 [28]. Figure 12 shows viscosity by the temperature at various mass fractions in shear rates of 12.23 and 122.3 [29]. As it can be seen by increasing mass fraction, viscosity increased. However, by increasing in temperature, viscosity decreased. Figure 13 shows $3 \mathrm{D}$ results of viscosity by both temperature and mass fraction in shear rates of 12.23 and 122.3 . 


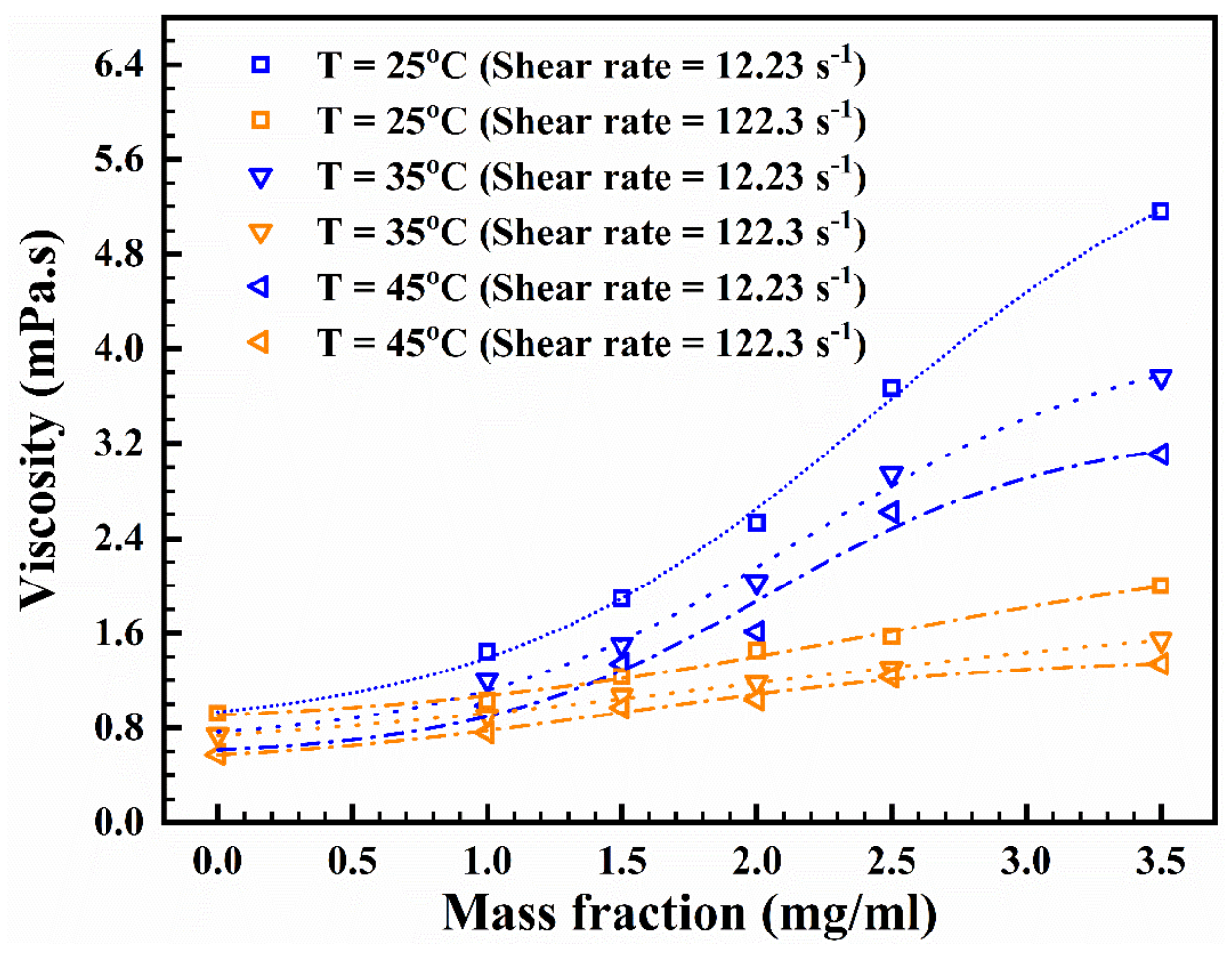

Figure 11. Viscosity profiles versus concentration

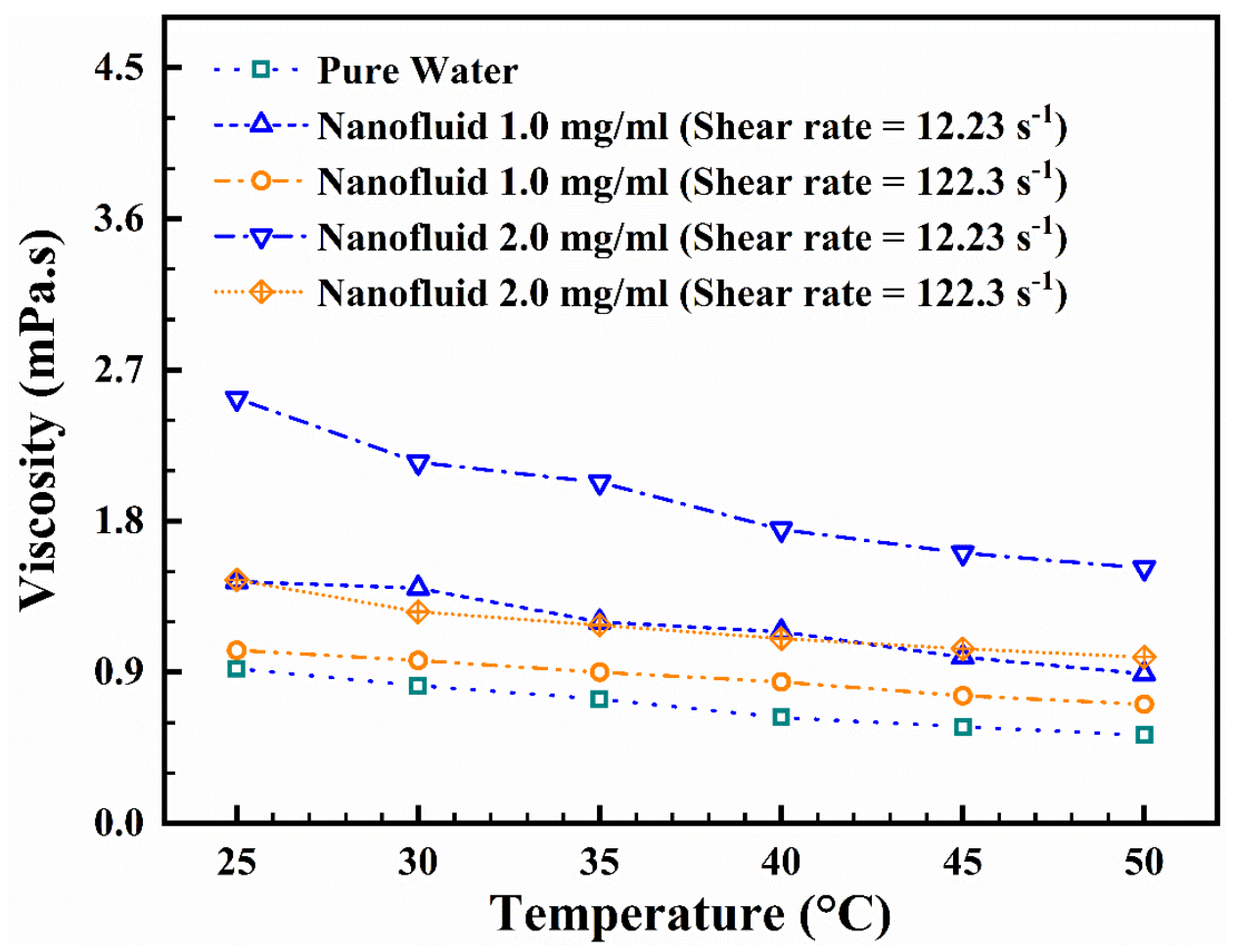

Figure 12. Viscosity profiles versus temperature 


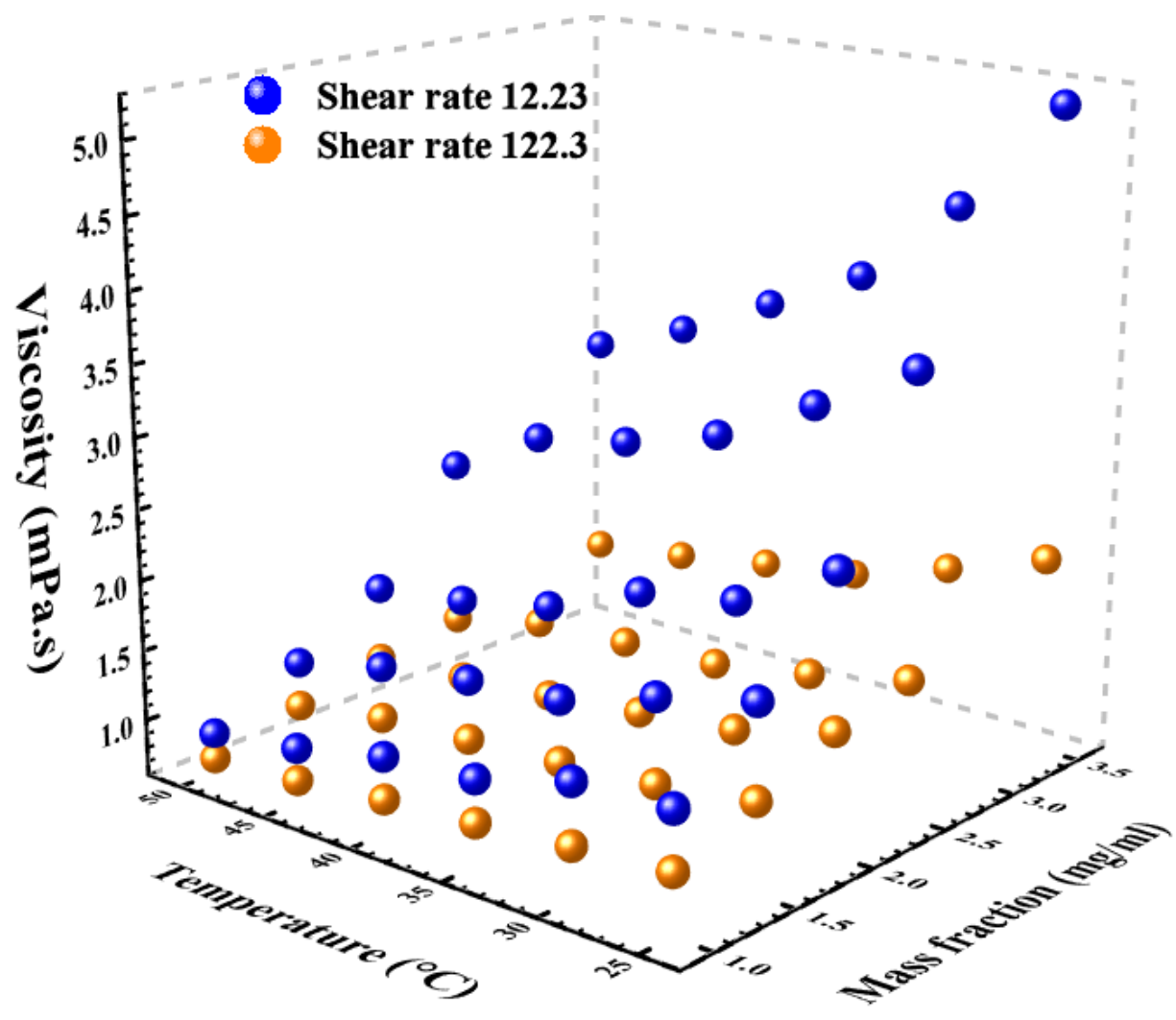

Figure 13. Three-dimensional view of Experimental data for viscosity at various nanofluid mass fractions and temperatures and

\section{Non-Newtonian behavior}

The rheological behavior of nanofluids could be characterized, because of the flow behavior under applied external pressure and also a response to shear stress. Also, the effects caused by the shear stress are more important than the pressure because most liquids are considered as an incompressible fluid. Fluids have Newtonian behavior when shear stress $(\tau)$ is linearly proportional to the shear rate $(\gamma)$ and their viscosity $(\mu)$ remains constant. Though, for non-Newtonian fluids, viscosity is a function of shear rate and shear stress or varies at various shear rates. Non-Newtonian fluids are: Time-dependent, Time-independent and Viscoelastic [30], [31].

1) Time-dependent: which is at constant shear rates, the viscosity of fluids modifies by time. By increasing the shear rate in these types of fluids, If the viscosity increases with time, the fluids are rheopectic and if decreases with time, they are called thixotropic. 
2) Time-independent: which has no memory of their past history or not dependent on the time of applying the shear rate. In Time-independent category, Bingham fluids have initial yield stress (need initial tension to flow) [32].

3) Viscoelastic fluids: which exhibit both viscous and elastic characteristics, after undergoing deformation can be converted into the initial state.

Figure 14, shows nanofluid viscosity and shear stress by shear rate for mass fractions 1.0 to 3.5 $\mathrm{mg} / \mathrm{ml}$ and temperatures 25 to $50^{\circ} \mathrm{C}$. This figure shows that the rheological behavior of nanofluid is non-Newtonian. As mentioned above, non-Newtonian fluid type divided into Time-dependent and Time-independent (which divided into Shear-thinning and Shear-thickening) [33]. For Graphene Oxide, power (in pawer law equation) is less than one and so, pseudoplastic type (Shearthinning) happened [34]. Equation (05) for pawer law is:

$$
\tau=m \dot{\Upsilon}^{n}
$$

Where $\tau$ is shear stress $(\mathrm{Pa}), \gamma$ is shear rate $\left(s^{-1}\right), \mathrm{m}$ is flow consistency index $\left(\mathrm{Pa} . S^{n}\right)$, and $\mathrm{n}$ is the power-law index (dimensionless).

Also, obvious viscosity is calculated from Equation (06) as:

$$
\mu=m \dot{\Upsilon}^{n-1}
$$

where $\mu$ stands for obvious nanofluid viscosity [35].

It can be seen the trend of viscosity or shear stress by shear rate is non-linear. $m$ and $n$ values at any mass fraction and temperature can be calculated by using Equation (07) and curve-fitting method.

$$
\tau=\mu \dot{\Upsilon}
$$



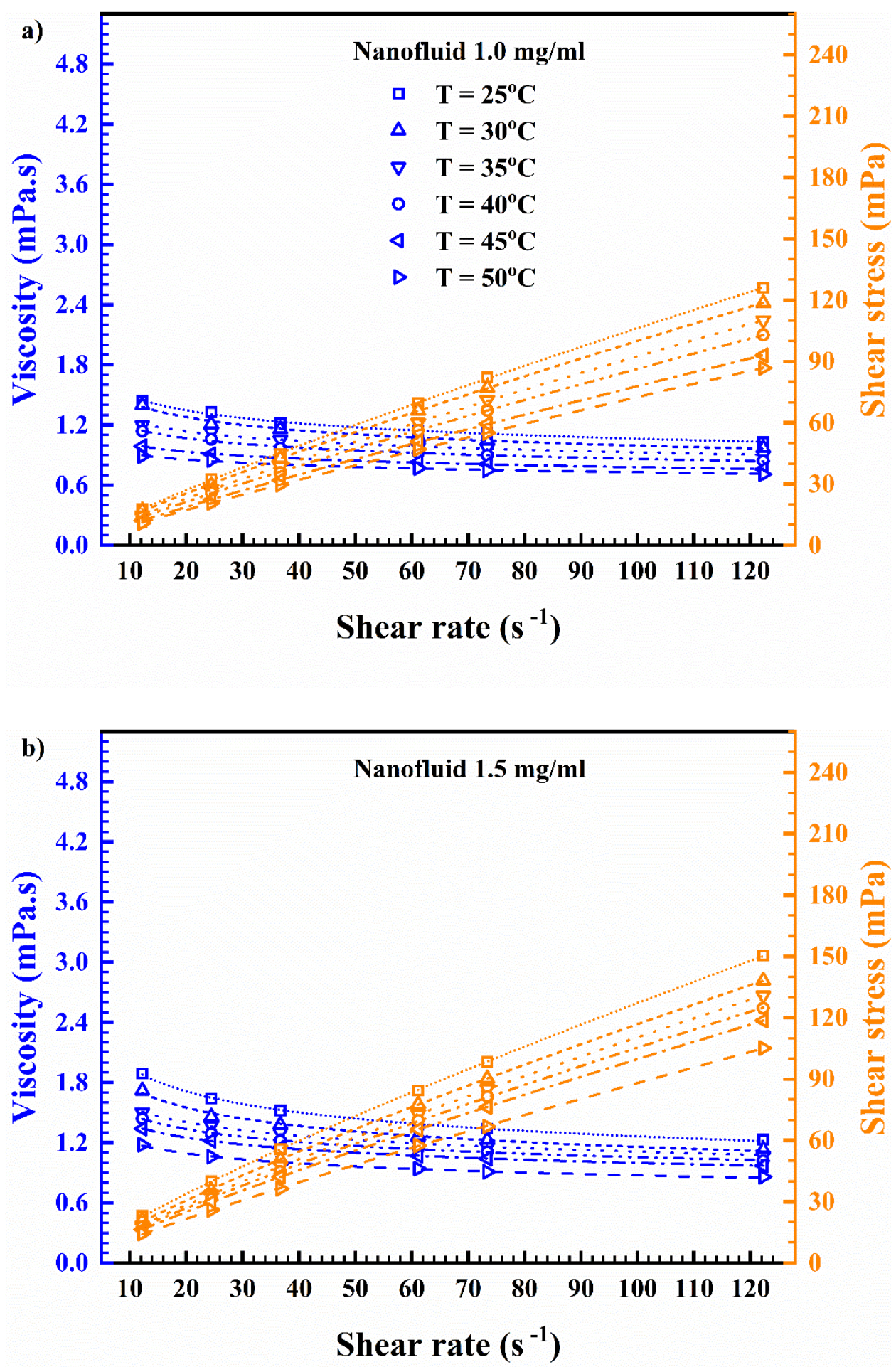

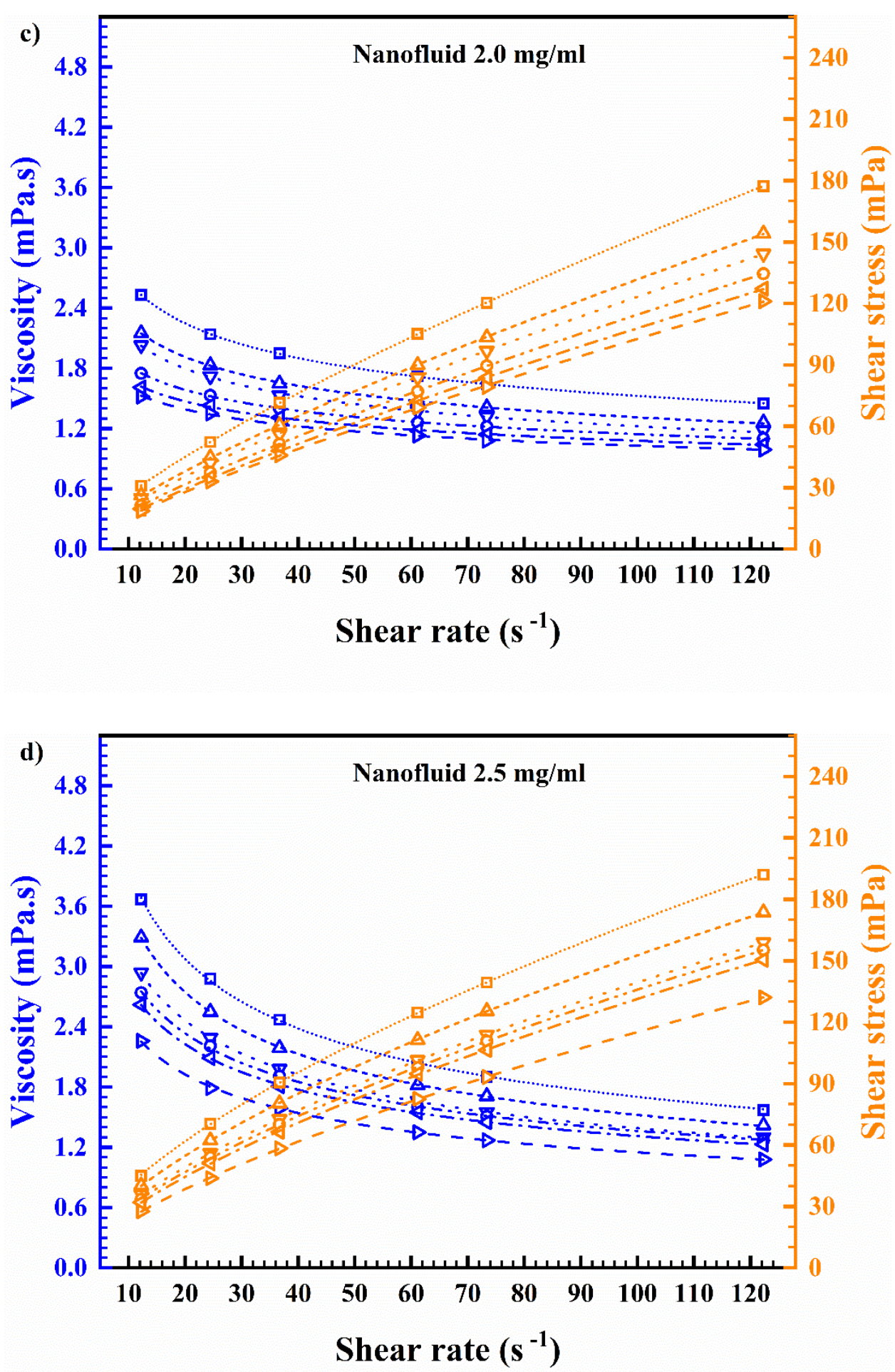


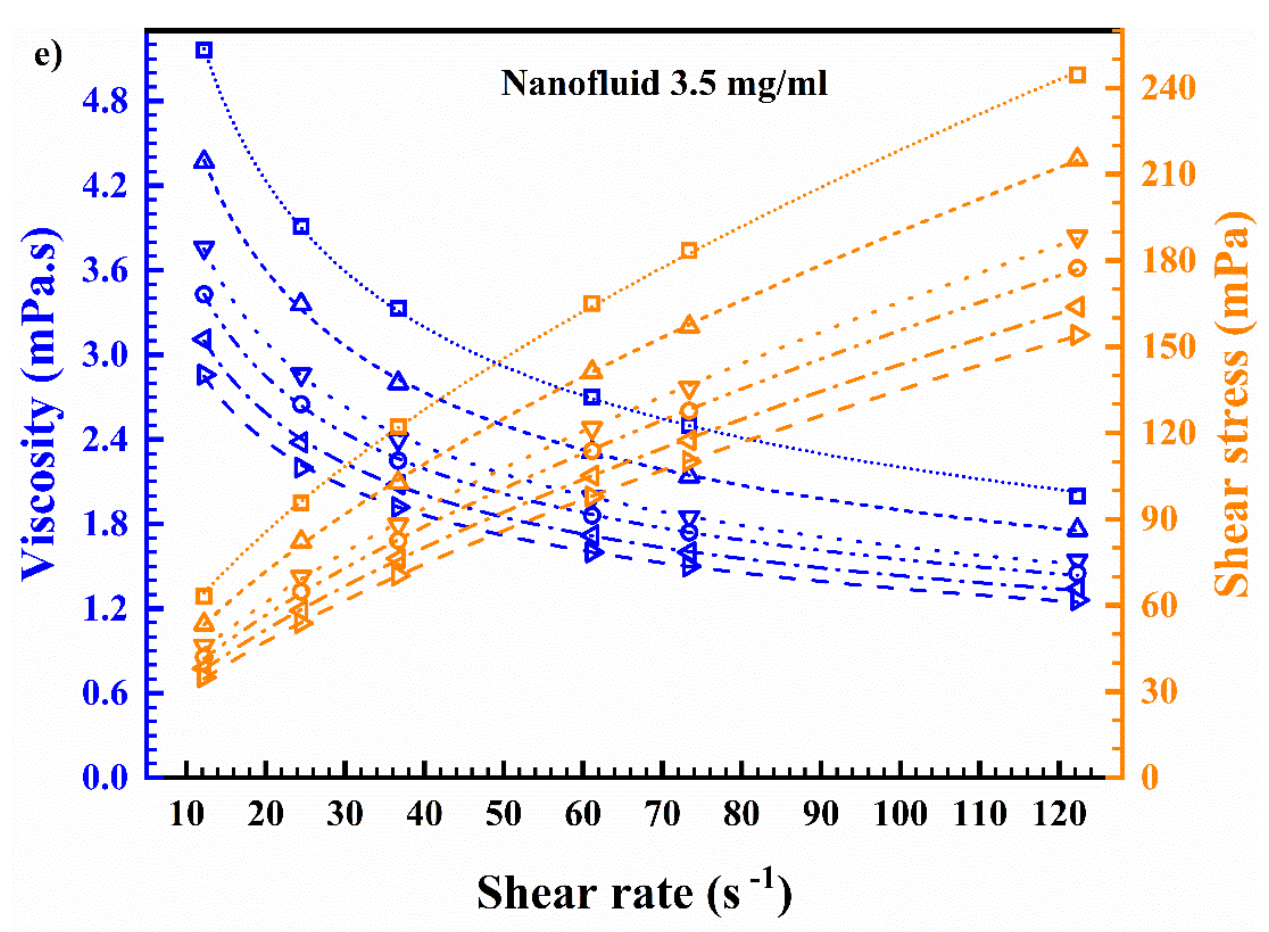

Figure 14. Viscosity and Shear stress variations for (a) $1.0 \mathrm{mg} / \mathrm{ml}$, (b) $1.5 \mathrm{mg} / \mathrm{ml}$, (c) $2.0 \mathrm{mg} / \mathrm{ml}$, (d) $2.5 \mathrm{mg} / \mathrm{ml}$ and (e) $3.5 \mathrm{mg} / \mathrm{ml}$ by shear rate

By considering nanofluid's non-Newtonian behavior, and results of Figure 14, $\mathrm{m}$ and $\mathrm{n}$ parameters obtained in Figure 15. As can be seen, Figure 15. a shows the consistency index (m). For each mass fraction, by increasing the temperature, $m$ decreased, however in general view, by increasing mass fraction, $m$ increased [36]. Also, Figure 15.b shows the pawer law index (n). For each mass fraction, by increasing temperature, $\mathrm{n}$ increased, however in general view, by increasing mass fraction, $\mathrm{n}$ decreased [37]. This behavior is logical due to decrement of viscosity by increasing temperature which causes nanofluid acts more likely to water basefluid (which has Newtonian behavior). 

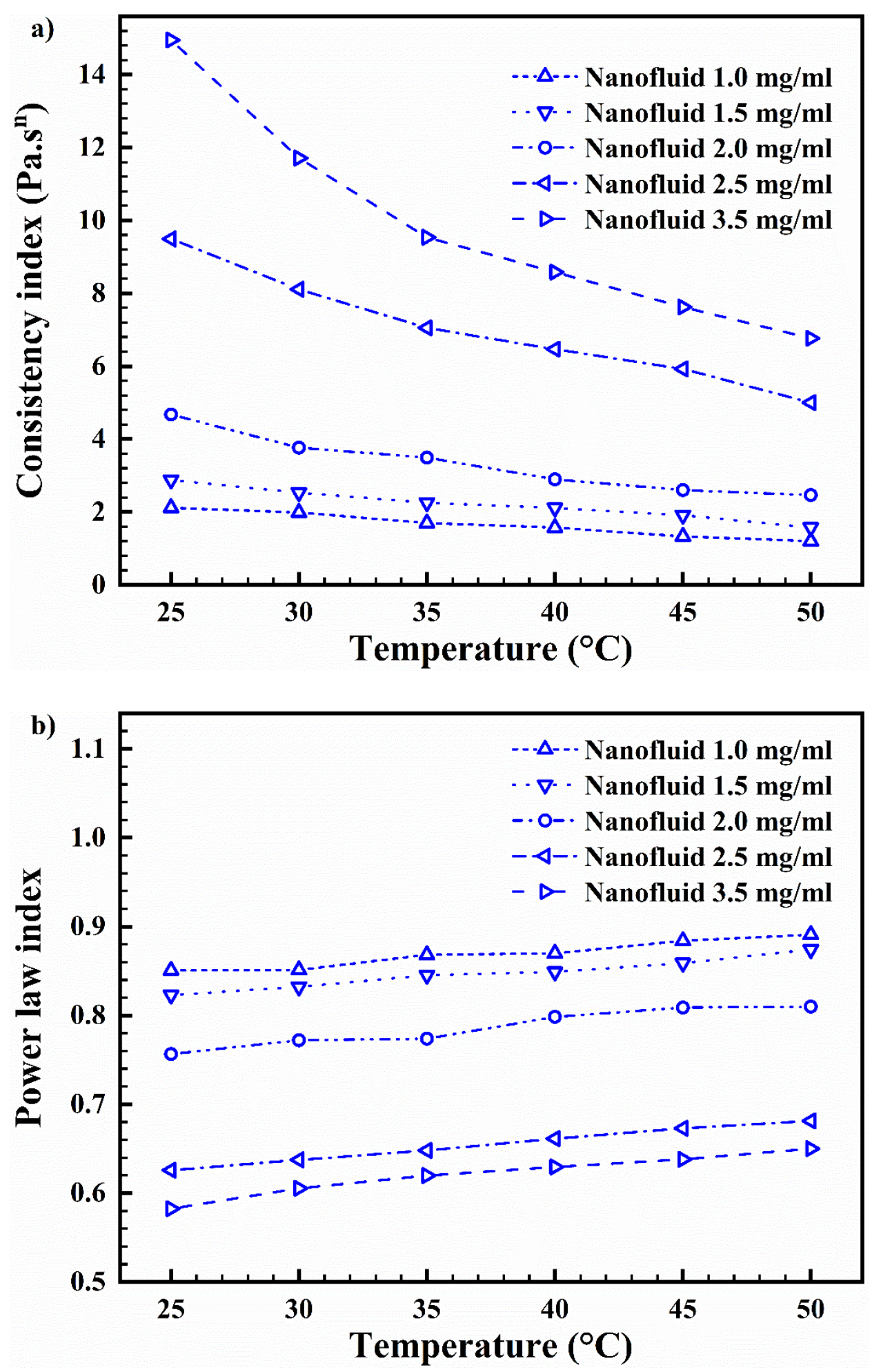

Figure 15. Variations in (a) Consistency index and (b) power-law index by temperature 


\subsection{Numerical Study}

\section{Proposed Correlation}

A new correlation to calculate viscosity of Graphene-Water nanofluid offered by using a curvefitting method (Equations 08 and 09). R2 for this correlation was about 0.99 [38]. Figure 16 shows the $3 \mathrm{D}$ fitted equation on experimental data for both 12.23 and 122.3 shear rates.

$\mathrm{R}^{2}$ for shear rate $12.23(10 \mathrm{RPM})$ is 0.9966 and its correlation reported as:

$$
\mathrm{Vis}=\left[1.39544 * T^{-0.78823}\right] *\left[w t^{1.02734}\right]
$$

$\mathrm{R}^{2}$ for shear rate 122.3 (100 RPM) is 0.9993 and its correlation reported as:

$$
\mathrm{Vis}=\left[1.05301 * T^{-0.55613}\right]^{*}\left[w t^{0.46584}\right]
$$

Where viscosity is in centipoise, $\mathrm{T}$ stands for temperature in Celsius and wt is mass fraction [39].

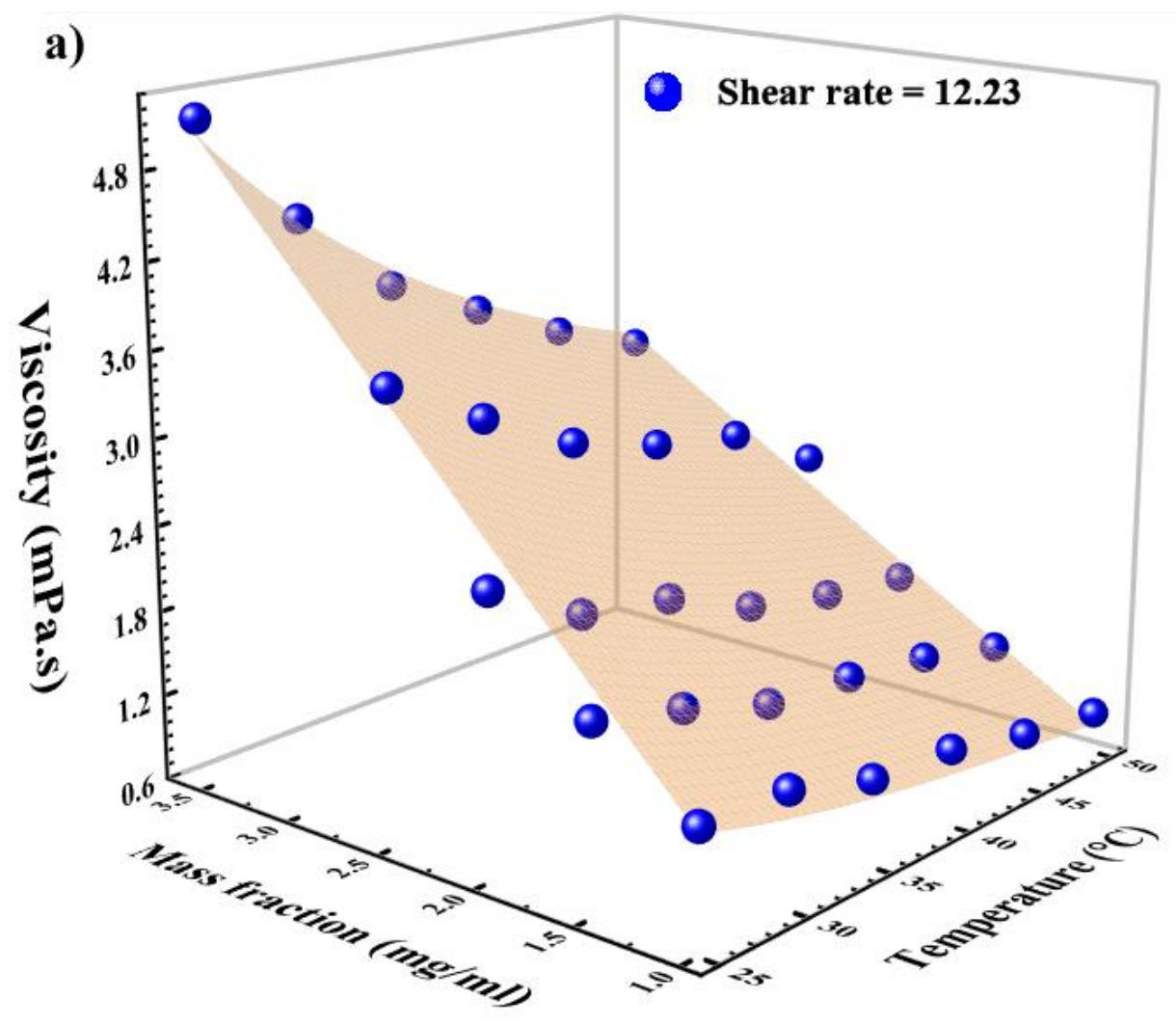




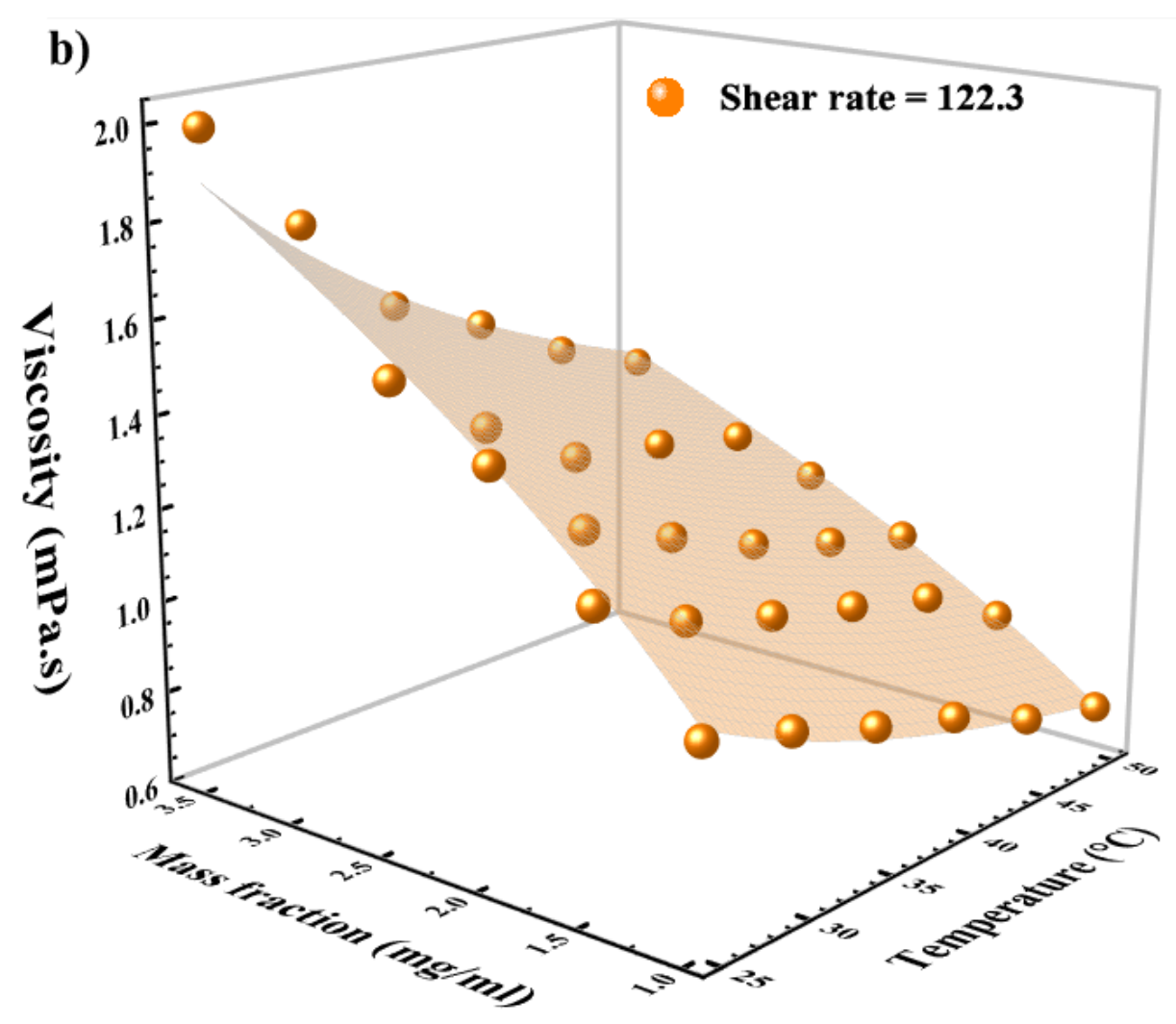

Figure 16. Verify presented correlation by experimental results; viscosity by temperature and mass fraction of nanofluid for a) 10 RPM and b) 100 RPM

To verify the presented correlation by experimental data of viscosity, Equation 10 used to compute deviation. Figure 17 shows the highest deviation of margin calculated $1.88 \%$ (for RPM=10) and $0.56 \%$ (for RPM $=100$ ), shows that proposed correlation is valid and has high accuracy [40].

$$
\operatorname{Dev}=\left[\frac{\mu_{E x p}-\mu_{\text {Pred }}}{\mu_{\text {Pred }}}\right] * 100
$$



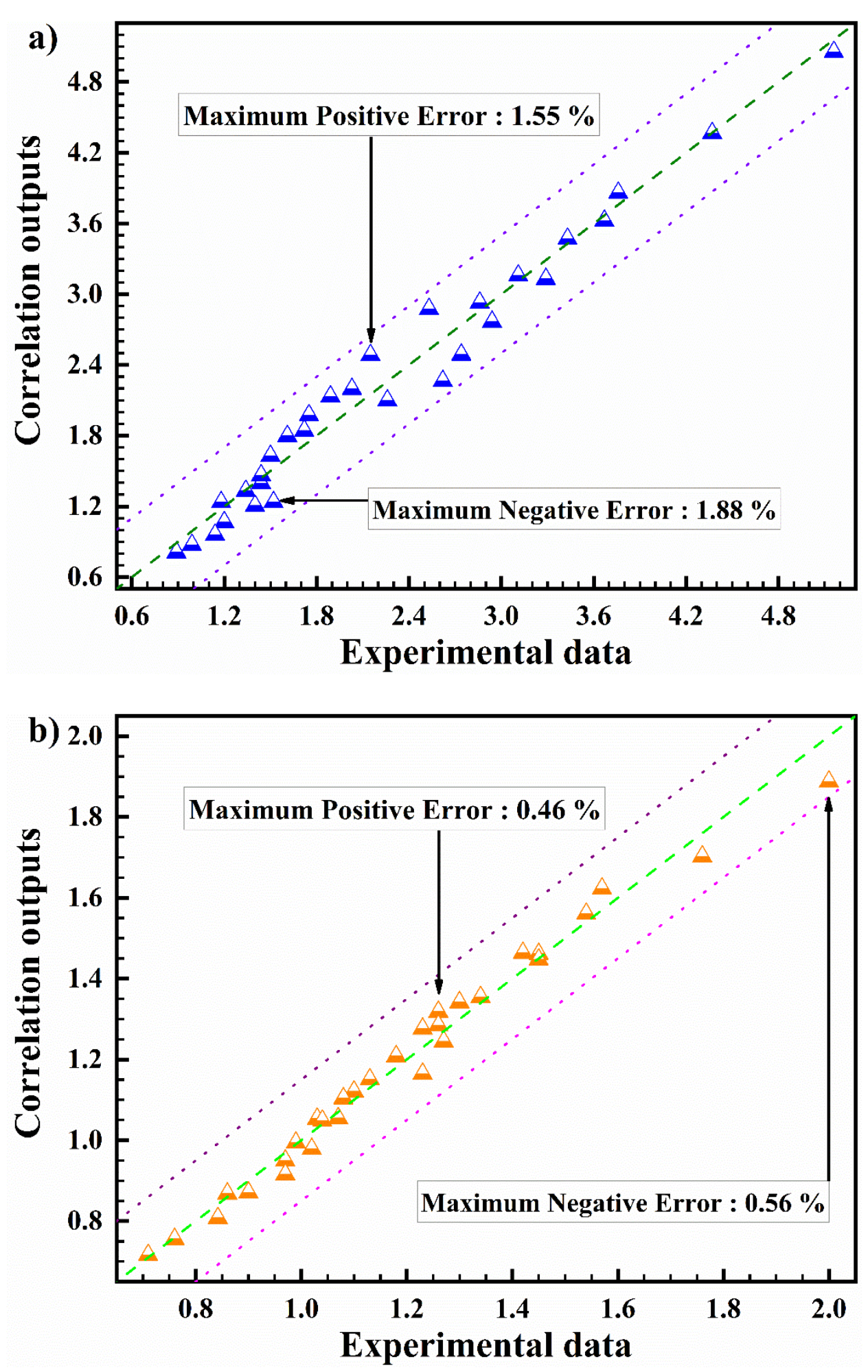

Figure 17. Verify presented correlation by experimental results for a) 10 RPM and b) 100 RPM 


\section{Artificial Neural Network}

This paper aims to model the viscosity of Graphene Oxide. This model has three inputs namely the temperature, mass fraction and shear rate and also, one output namely the viscosity. To that end, an Artificial Neural Network (ANN) model is utilized. The ANN has one hidden layer and one output layer. The hidden layer has 16 sigmoid neurons while the output layer has a linear transfer function. The architecture of the ANN is illustrated in Figure 18. The Bayesian regularization backpropagation is employed as the training algorithm.

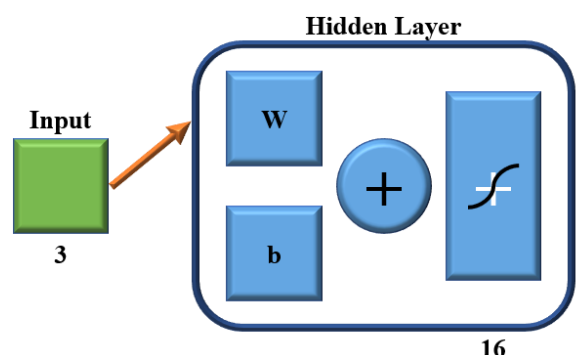

16

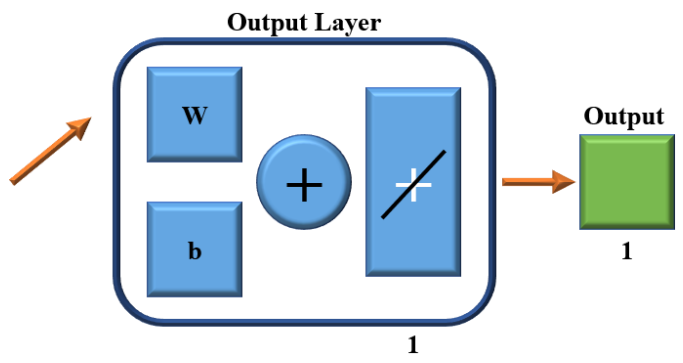

Figure 18. The architecture of the ANN

There are two training datasets for the shear rates of $12.23(1 / \mathrm{s})$ and $122.3(1 / \mathrm{s})$. Every training dataset has 36 samples obtained by the experiment. The training datasets for the investigated shear rates are illustrated in Figure 19 [41,42].

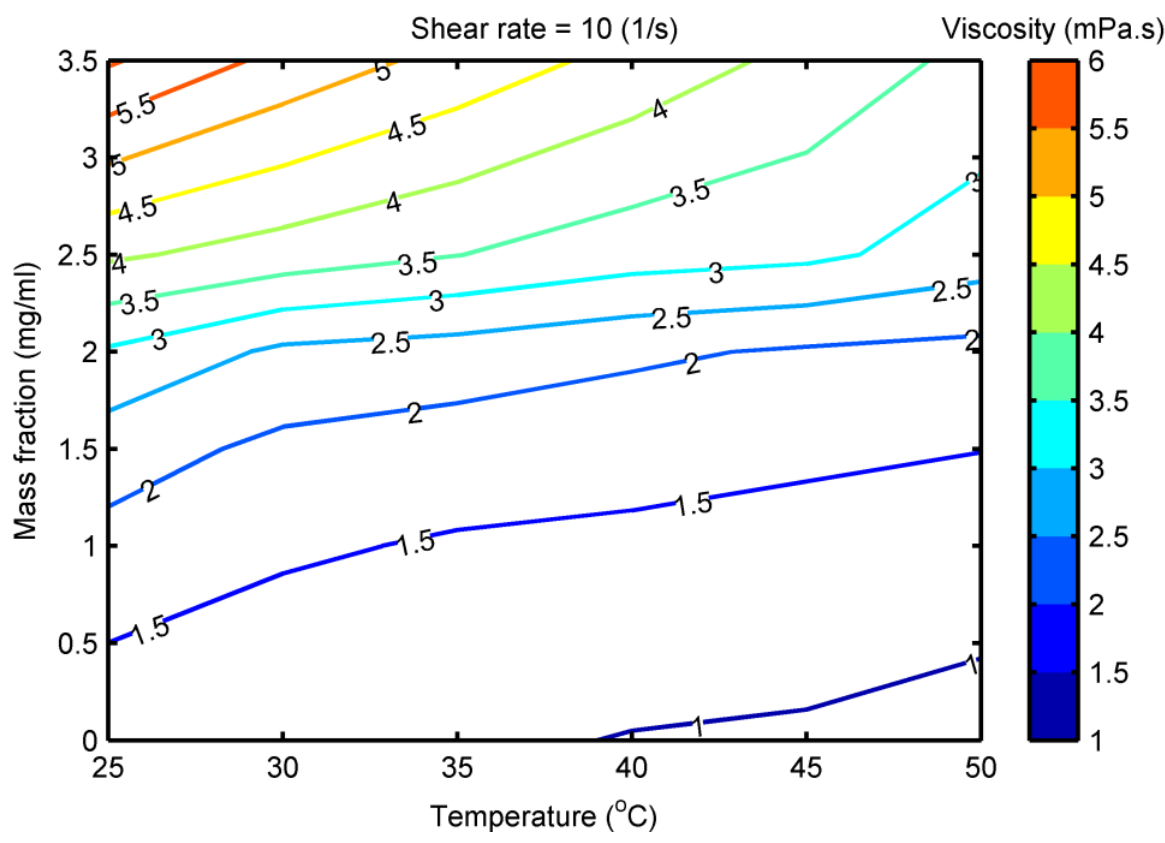

(a) 


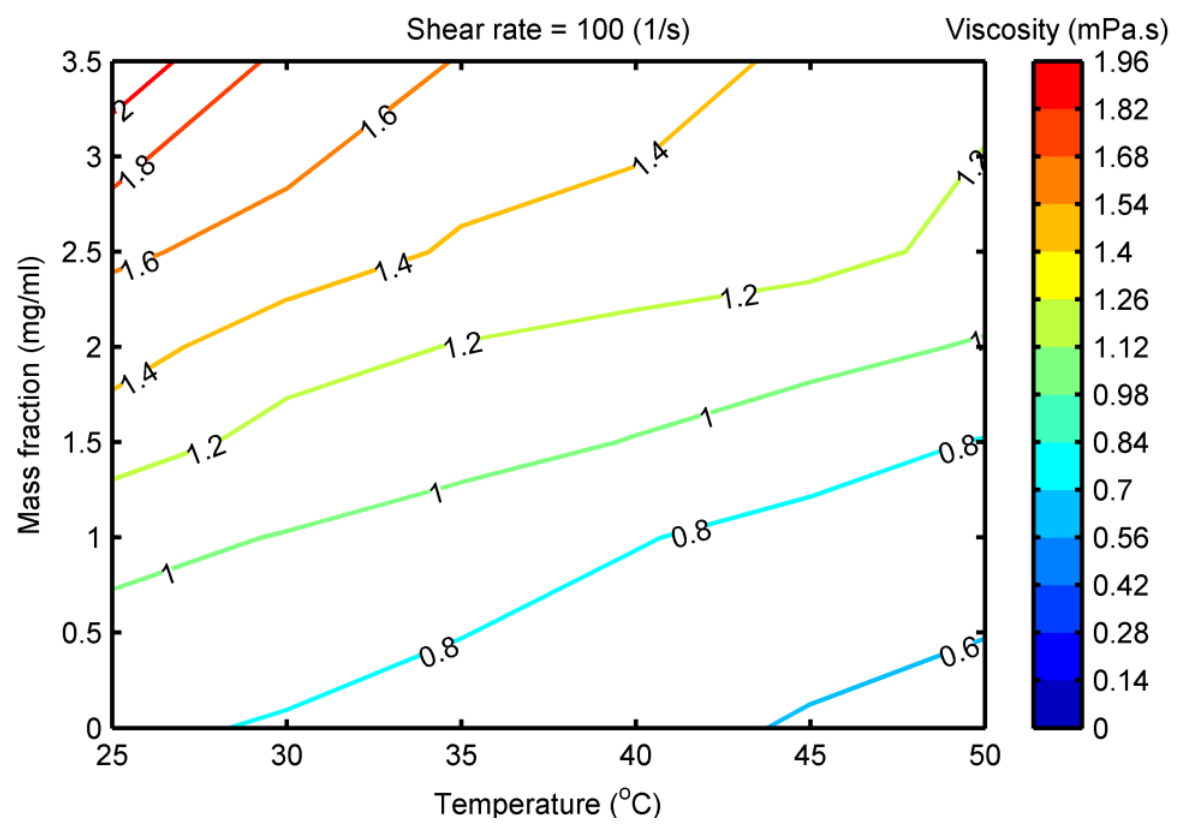

(b)

Figure 19. The training dataset for shear rates of (a) $12.23(1 / \mathrm{s})$ and (b) $122.3(1 / \mathrm{s})$

The regression plots for the ANN model is illustrated in Figure 20. In this diagram, the numerical viscosity predicted by the ANN model is plotted against the experimental viscosity. In an ideal case, the numerical and experimental viscosities should be identical. In other words, the slope, and bias values of the fitted line should equal to 1 and 0, respectively. Hence, ANN model provides an acceptable model because the slope and bias values of the fitted regression plot are 0.997, 0.004, respectively. Moreover, the regression value is 0.9996 that indicates a suitable regression fit. 


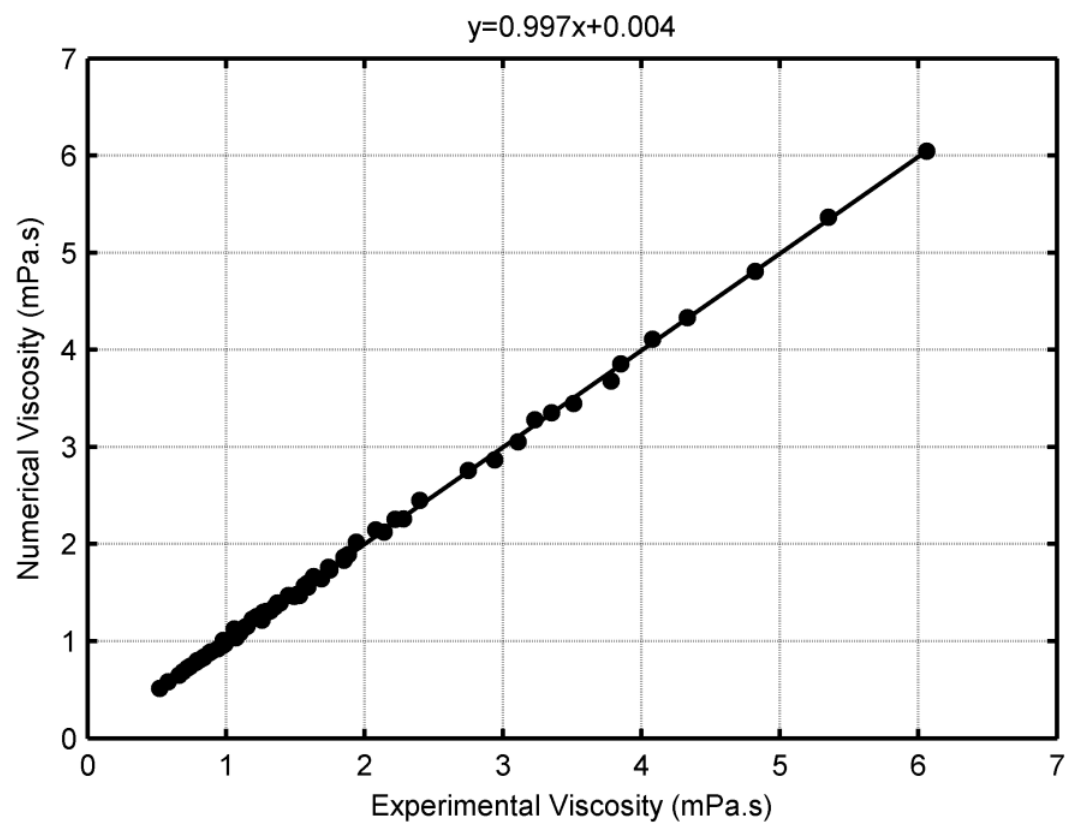

Figure 20. The regression plots for the ANN model

The prediction error of the ANN model is illustrated in Figure 21. In this figure, the error percentages are plotted against the experimental viscosity. It can be seen that the maximum error percentage is about $6 \%$ while the error percentages are generally less than $3 \%$. Also, the error histogram illustrated in Figure 22. shows the error distribution.

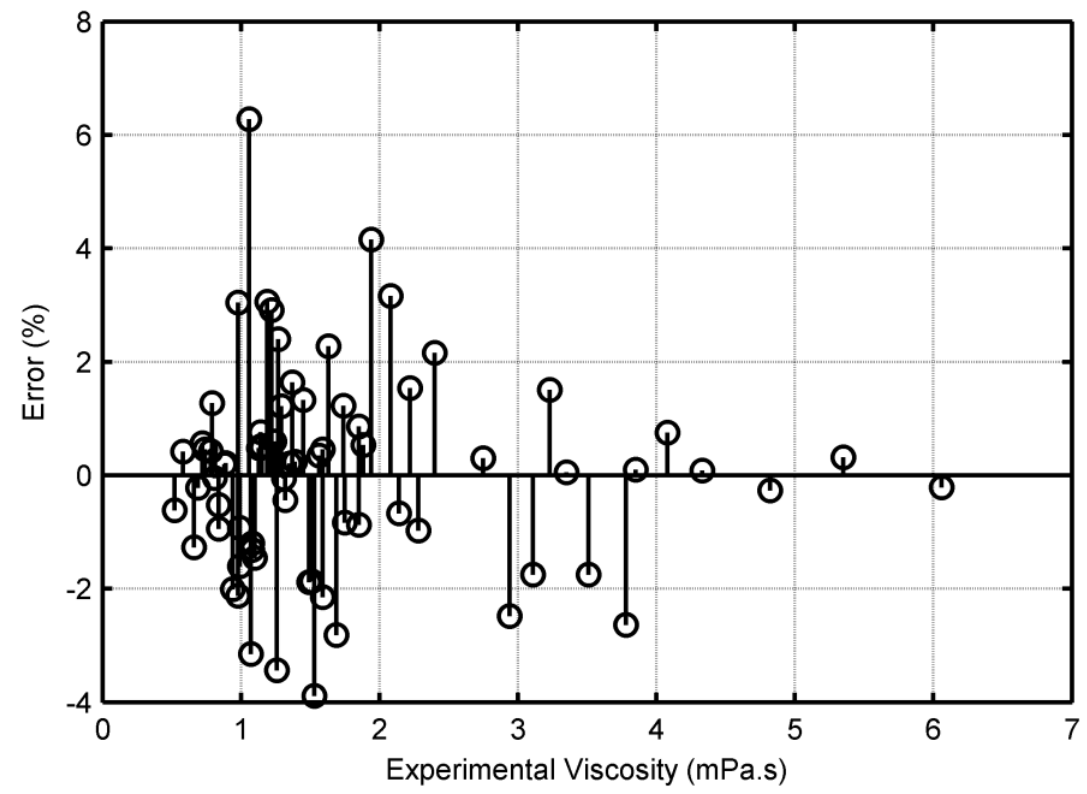

Figure 21. The prediction error of the ANN model 


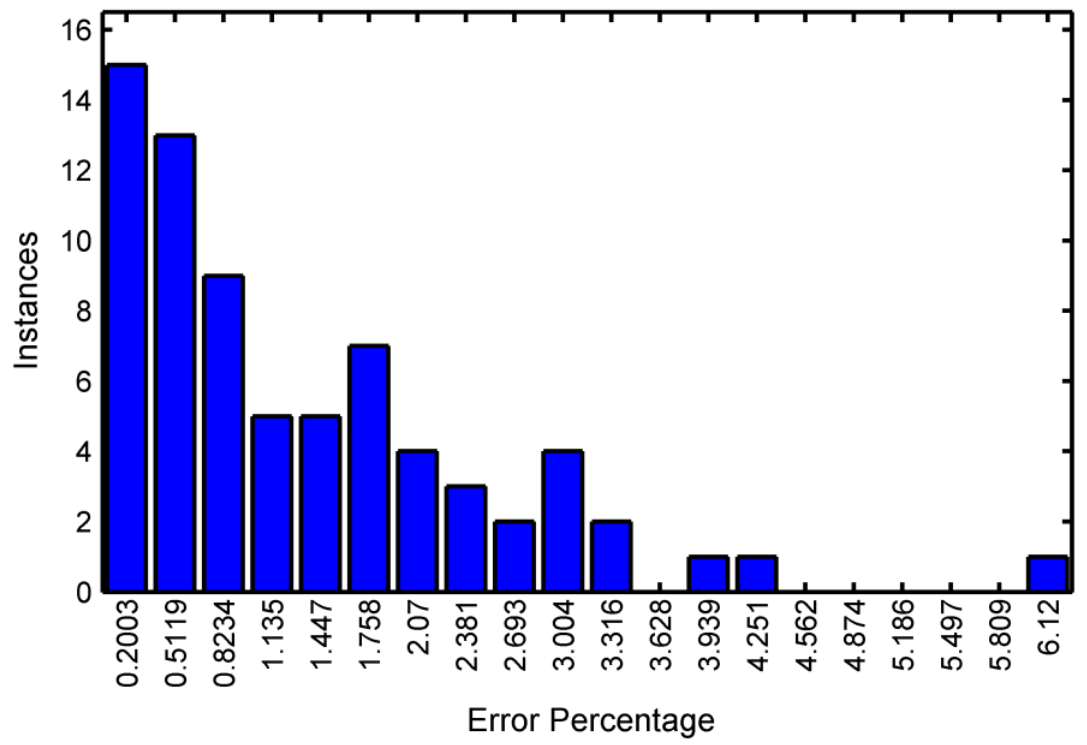

Figure 22. The error histogram

Once the ANN model is obtained, the viscosity can be predicted in the investigated domain of the temperature, mass fraction and shear rate. Figure 23. shows the numerical viscosities predicted by the ANN model as contours. Every contour displays the viscosity as a function of the temperature and mass fraction at a constant shear rate. It can be observed that the shear rate severely effects the predicted viscosity. The higher the shear rate, the lower the predicted viscosity. Also, it can be seen that the viscosity increases with mass fraction while it decreases with the temperature. However, the mass fraction is more effective on the predicted viscosity than the temperature. Since the numerical values of the viscosity are obtained in non-trained shear rates, temperatures and mass fractions, the ANN is successful in the prediction of the nanofluid behaviors. 


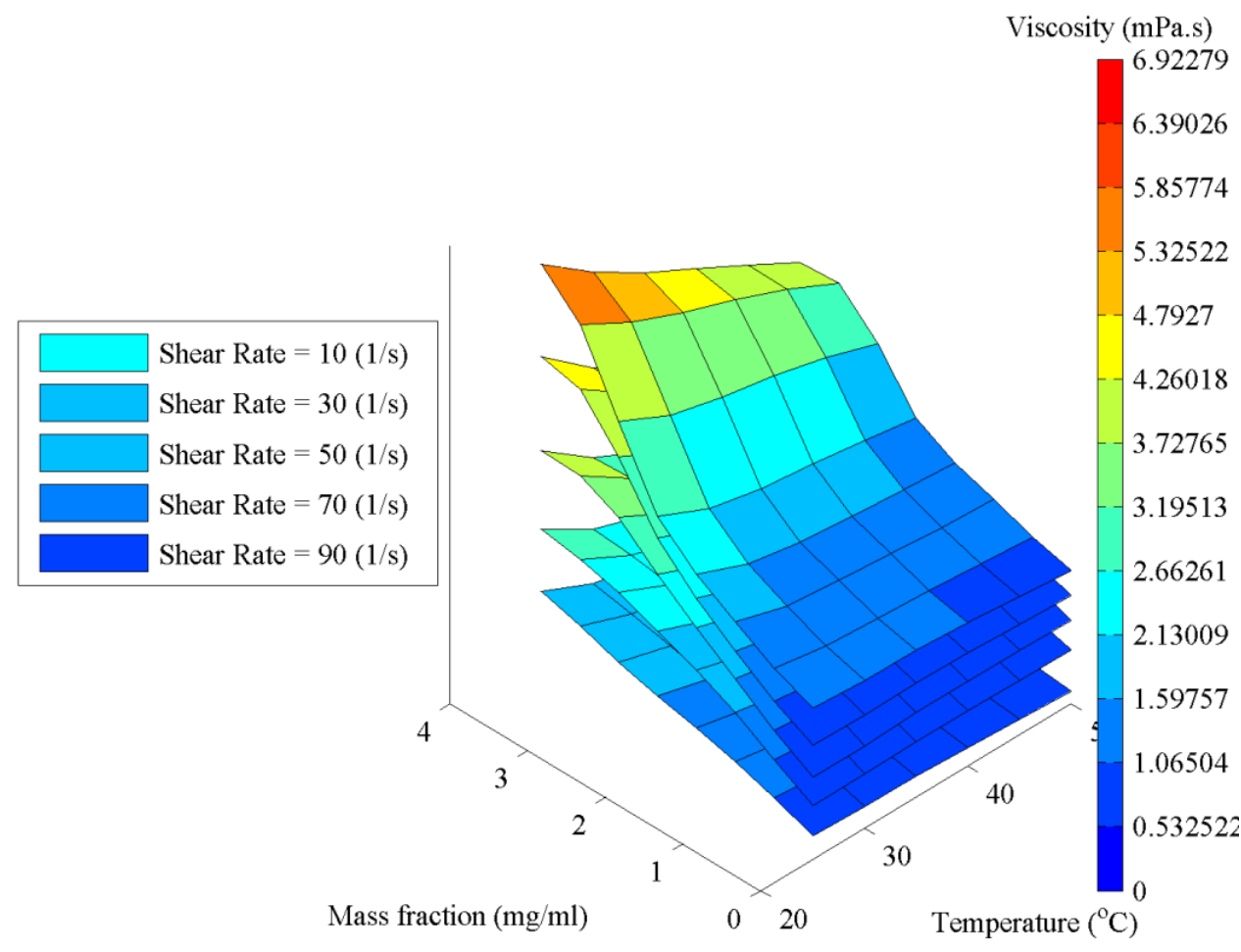

Figure 23. The numerical viscosities predicted by the ANN model in the investigated domain of outputs (the higher the shear rate, the lower the predicted viscosity)

\section{Conclusion}

In this study, dynamic viscosity of Graphene Oxide-Water nanofluid at mass fractions of 1.0 to $3.5 \mathrm{mg} / \mathrm{ml}$ and temperature ranges of 25 to $50^{\circ} \mathrm{C}$ measured. Water has Newtonian behavior; however, when GO added to basefluid, nanofluid showed non-Newtonian behavior [43]. Viscosity increases by increasing mass fraction and decreases by increasing temperature. Nanofluid followed a power-law model. Power law model indices ( $m$ and $n$ ) found for all mass fractions and temperatures. By experimental results and curve-fitting, a correlation which shows very high accuracy, for both 12.23 and 122.3 shear rates calculated [44]. Then, correlation validated and $1.88 \%$ (for RPM $=10$ ) and $0.56 \%$ (for RPM=100) deviation reported [45]. A list of results listed as:

- GO, a 2D material, synthesized via modified hummers' method and then, a stable and homogeneous nanofluid has been prepared. 
- By adding GO, basefluid viscosity increased and pseudoplastic behaviour reported due to the study of shear rate by shear stress.

- Zeta potential test revealed GO-water acceptable stability of nanofluid.

- Correlation presented in this paper, has the R-Squared (deviation) of about 0.99. Thus, it can calculate GO-Water viscosity in further researches.

- ANN modeled in this paper, has the R-Squared (deviation) of about 0.997. Thus, it can predict viscosity of other mass fractions and temperatures.

\section{Conflicts of Interest}

There is no conflict of interest.

\section{Acknowledgement:}

This research is partially supported by NSFC (No. 51979261), Australia Research Council (No. DE190100931), Fujian Province Natural Science Foundation (No. 2018J01506) and Taishan Scholar of Shandong Province, China (tsqn201801225).

\section{References}

[1] J. Chen, Y. Li, L. Huang, C. Li, and G. Shi, "High-yield preparation of graphene oxide from small graphite flakes via an improved Hummers method with a simple purification process," Carbon N. Y., vol. 81, pp. 826-834, Jan. 2015.

[2] C. Fu, G. Zhao, H. Zhang, and S. Li, "Evaluation and characterization of reduced graphene oxide nanosheets as anode materials for lithium-ion batteries," Int. J. Electrochem. Sci., vol. 8, no. 5, pp. 6269-6280, 2013.

[3] S. N. Alam, N. Sharma, and L. Kumar, "Synthesis of Graphene Oxide (GO) by Modified Hummers Method and Its Thermal Reduction to Obtain Reduced Graphene Oxide (rGO)*," Graphene, vol. 06, no. 01, pp. 1-18, 2017. 
[4] L. Stobinski et al., "Graphene oxide and reduced graphene oxide studied by the XRD, TEM and electron spectroscopy methods," J. Electron Spectros. Relat. Phenomena, vol. 195, pp. 145154, Aug. 2014.

[5] D. C. Marcano et al., "Correction to Improved Synthesis of Graphene Oxide," ACS Nano, vol. 12, no. 2, pp. 2078-2078, Feb. 2018.

[6] C. R. Minitha and R. T. Rajendrakumar, "Synthesis and Characterization of Reduced Graphene Oxide," Adv. Mater. Res., vol. 678, pp. 56-60, Mar. 2013.

[7] S. Pei and H.-M. Cheng, "The reduction of graphene oxide," Carbon N. Y., vol. 50, no. 9, pp. 3210-3228, Aug. 2012.

[8] J. Chen, B. Yao, C. Li, and G. Shi, "An improved Hummers method for eco-friendly synthesis of graphene oxide," Carbon N. Y., vol. 64, no. 1, pp. 225-229, Nov. 2013.

[9] H. Eshgarf, N. Sina, M. H. Esfe, F. Izadi, and M. Afrand, "Prediction of rheological behavior of MWCNTs-SiO2/EG-water non-Newtonian hybrid nanofluid by designing new correlations and optimal artificial neural networks," J. Therm. Anal. Calorim., vol. 132, no. 2, pp. 1029-1038, May 2018.

[10] M. Ghanbarpour, E. Bitaraf Haghigi, and R. Khodabandeh, "Thermal properties and rheological behavior of water based $\mathrm{A} 12 \mathrm{O} 3$ nanofluid as a heat transfer fluid," Exp. Therm. Fluid Sci., vol. 53, pp. 227-235, Feb. 2014.

[11] S. Abbasi, S. M. Zebarjad, S. H. N. Baghban, A. Youssefi, and M.-S. Ekrami-Kakhki, "Experimental investigation of the rheological behavior and viscosity of decorated multi-walled carbon nanotubes with $\mathrm{TiO} 2$ nanoparticles/water nanofluids," J. Therm. Anal. Calorim., vol. 123, no. 1, pp. 81-89, Jan. 2016.

[12] E. Abu-Nada, "Effects of variable viscosity and thermal conductivity of Al2O3-water nanofluid on heat transfer enhancement in natural convection," Int. J. Heat Fluid Flow, vol. 30, no. 4, pp. 679-690, Aug. 2009.

[13] H. Li, L. Wang, Y. He, Y. Hu, J. Zhu, and B. Jiang, "Experimental investigation of thermal conductivity and viscosity of ethylene glycol based ZnO nanofluids," Appl. Therm. Eng., vol. 88, pp. 363-368, Sep. 2015.

[14] F. Jabbari, A. Rajabpour, and S. Saedodin, "Thermal conductivity and viscosity of nanofluids: A review of recent molecular dynamics studies," Chem. Eng. Sci., vol. 174, pp. 6781, Dec. 2017. 
[15] Y. R. Sekhar and K. V. Sharma, "Study of viscosity and specific heat capacity characteristics of water-based A1 2 O 3 nanofluids at low particle concentrations," J. Exp. Nanosci., vol. 10, no. 2, pp. 86-102, Jan. 2015.

[16] A. S. Dalkılıç et al., "Experimental investigation on the viscosity characteristics of water based SiO2-graphite hybrid nanofluids," Int. Commun. Heat Mass Transf., vol. 97, pp. 30-38, Oct. 2018.

[17] M. Bahrami, M. Akbari, A. Karimipour, and M. Afrand, "An experimental study on rheological behavior of hybrid nanofluids made of iron and copper oxide in a binary mixture of water and ethylene glycol: Non-Newtonian behavior," Exp. Therm. Fluid Sci., vol. 79, pp. 231237, Dec. 2016.

[18] O. Accessories, "DV2T Viscometer Manual."

[19] A. García, M. Culebras, M. N. Collins, and J. J. Leahy, "Stability and rheological study of sodium carboxymethyl cellulose and alginate suspensions as binders for lithium ion batteries," $J$. Appl. Polym. Sci., vol. 135, no. 17, p. 46217, May 2018.

[20] T. X. Phuoc, M. Massoudi, and R. Chen, "Viscosity and thermal conductivity of nanofluids containing multi-walled carbon nanotubes stabilized by chitosan," Int. J. Therm. Sci., vol. 50, no. 1, pp. 12-18, Jan. 2011.

[21] A. Shahsavar, M. R. Salimpour, M. Saghafian, and M. B. Shafii, "Effect of magnetic field on thermal conductivity and viscosity of a magnetic nanofluid loaded with carbon nanotubes," $J$. Mech. Sci. Technol., vol. 30, no. 2, pp. 809-815, Feb. 2016.

[22] A. Ahmadi Nadooshan, H. Eshgarf, and M. Afrand, "Measuring the viscosity of Fe3O4MWCNTs/EG hybrid nanofluid for evaluation of thermal efficiency: Newtonian and nonNewtonian behavior," J. Mol. Liq., vol. 253, no. 2017, pp. 169-177, Mar. 2018.

[23] E. Shahsavani, M. Afrand, and R. Kalbasi, "Experimental study on rheological behavior of water-ethylene glycol mixture in the presence of functionalized multi-walled carbon nanotubes," J. Therm. Anal. Calorim., vol. 131, no. 2, pp. 1177-1185, Feb. 2018.

[24] F. Jabbari, A. Rajabpour, and S. Saedodin, "Viscosity of carbon nanotube/water nanofluid," J. Therm. Anal. Calorim., vol. 135, no. 3, pp. 1787-1796, Feb. 2019.

[25] S. Bhattacharjee, "DLS and zeta potential - What they are and what they are not?," J. Control. Release, vol. 235, pp. 337-351, Aug. 2016.

[26] ASHRAE, 2015 Ashrae Handbook. 2015. 
[27] J. Jeong, C. Li, Y. Kwon, J. Lee, S. H. Kim, and R. Yun, "Particle shape effect on the viscosity and thermal conductivity of ZnO nanofluids," Int. J. Refrig., vol. 36, no. 8, pp. 22332241, Dec. 2013.

[28] P. K. Namburu, D. P. Kulkarni, D. Misra, and D. K. Das, "Viscosity of copper oxide nanoparticles dispersed in ethylene glycol and water mixture," Exp. Therm. Fluid Sci., vol. 32, no. 2, pp. 397-402, Nov. 2007.

[29] L. Syam Sundar, M. K. Singh, and A. C. M. Sousa, "Investigation of thermal conductivity and viscosity of Fe3O4 nanofluid for heat transfer applications," Int. Commun. Heat Mass Transf., vol. 44, pp. 7-14, May 2013.

[30] R. Zhang, S. Aghakhani, A. Hajatzadeh Pordanjani, S. M. Vahedi, A. Shahsavar, and M. Afrand, "Investigation of the entropy generation during natural convection of Newtonian and nonNewtonian fluids inside the L-shaped cavity subjected to magnetic field: application of lattice Boltzmann method," Eur. Phys. J. Plus, vol. 135, no. 2, p. 184, Feb. 2020.

[31] Afrand, M., Karimipour, A., Nadooshan, A.A. and Akbari, M., 2016. The variations of heat transfer and slip velocity of FMWNT-water nano-fluid along the micro-channel in the lack and presence of a magnetic field. Physica E: Low-Dimensional Systems and Nanostructures, 84, pp.474-481.

[32] I. Kazemi, M. Sefid, and M. Afrand, "A novel comparative experimental study on rheological behavior of mono \&amp; hybrid nanofluids concerned graphene and silica nanopowders: Characterization, stability and viscosity measurements," Powder Technol., vol. 366, pp. 216-229, Apr. 2020.

[33] T. X. Phuoc and M. Massoudi, "Experimental observations of the effects of shear rates and particle concentration on the viscosity of Fe2O3-deionized water nanofluids," Int. J. Therm. Sci., vol. 48, no. 7, pp. 1294-1301, Jul. 2009.

[34] W. Yu, H. Xie, L. Chen, and Y. Li, "Investigation of thermal conductivity and viscosity of ethylene glycol based ZnO nanofluid,” Thermochim. Acta, vol. 491, no. 1-2, pp. 92-96, Jul. 2009. [35] M. Hemmat Esfe, A. A. Abbasian Arani, M. Rezaie, W. Yan, and A. Karimipour, "Experimental determination of thermal conductivity and dynamic viscosity of $\mathrm{Ag}-\mathrm{MgO} / \mathrm{water}$ hybrid nanofluid," Int. Commun. Heat Mass Transf., vol. 66, pp. 189-195, Aug. 2015.

[36] K. Bashirnezhad et al., "Viscosity of nanofluids: A review of recent experimental studies," Int. Commun. Heat Mass Transf., vol. 73, pp. 114-123, Apr. 2016. 
[37] W. H. Azmi, K. V. Sharma, R. Mamat, G. Najafi, and M. S. Mohamad, "The enhancement of effective thermal conductivity and effective dynamic viscosity of nanofluids - A review," Renew. Sustain. Energy Rev., vol. 53, pp. 1046-1058, Jan. 2016.

[38] P. Ganesh Kumar, D. Sakthivadivel, M. Meikandan, V. S. Vigneswaran, and R. Velraj, "Experimental study on thermal properties and electrical conductivity of stabilized $\mathrm{H} 2 \mathrm{O}$-solar glycol mixture based multi-walled carbon nanotube nanofluids: developing a new correlation," Heliyon, vol. 5, no. 8, p. e02385, Aug. 2019.

[39] A. Karimipour, S. Ghasemi, M. H. K. Darvanjooghi, and A. Abdollahi, "A new correlation for estimating the thermal conductivity and dynamic viscosity of $\mathrm{CuO} /$ /iquid paraffin nanofluid using neural network method," Int. Commun. Heat Mass Transf., vol. 92, pp. 90-99, Mar. 2018.

[40] M. Afrand, E. Abedini, and H. Teimouri, "How the dispersion of magnesium oxide nanoparticles effects on the viscosity of water-ethylene glycol mixture: Experimental evaluation and correlation development," Phys. E Low-dimensional Syst. Nanostructures, vol. 87, pp. 273280, Mar. 2017.

[41] Karimipour, A., Nezhad, A.H., D’Orazio, A., Esfe, M.H., Safaei, M.R. and Shirani, E., 2015. Simulation of copper-water nanofluid in a microchannel in slip flow regime using the lattice Boltzmann method. European Journal of Mechanics-B/Fluids, 49, pp.89-99.

[42] M. Afrand, A. Ahmadi Nadooshan, M. Hassani, H. Yarmand, and M. Dahari, "Predicting the viscosity of multi-walled carbon nanotubes/water nanofluid by developing an optimal artificial neural network based on experimental data," Int. Commun. Heat Mass Transf., vol. 77, pp. 49-53, Oct. 2016.

[43] M. R. Esfahani, E. M. Languri, and M. R. Nunna, "Effect of particle size and viscosity on thermal conductivity enhancement of graphene oxide nanofluid," Int. Commun. Heat Mass Transf., vol. 76, pp. 308-315, Aug. 2016.

[44] N. Ahammed, L. G. Asirvatham, and S. Wongwises, "Effect of volume concentration and temperature on viscosity and surface tension of graphene-water nanofluid for heat transfer applications," J. Therm. Anal. Calorim., vol. 123, no. 2, pp. 1399-1409, Feb. 2016.

[45] M. Kole and T. K. Dey, "Investigation of thermal conductivity, viscosity, and electrical conductivity of graphene based nanofluids," J. Appl. Phys., vol. 113, no. 8, p. 084307, Feb. 2013. 
[46] Goodarzi, M., Safaei, M.R., Vafai, K., Ahmadi, G., Dahari, M., Kazi, S.N. and Jomhari, N., 2014. Investigation of nanofluid mixed convection in a shallow cavity using a two-phase mixture model. International Journal of Thermal Sciences, 75, pp.204-220.

[47] Safaei, M.R., Togun, H., Vafai, K., Kazi, S.N. and Badarudin, A., 2014. Investigation of heat transfer enhancement in a forward-facing contracting channel using FMWCNT nanofluids. Numerical Heat Transfer, Part A: Applications, 66(12), pp.1321-1340.

[48] Arani, A.A.A., Akbari, O.A., Safaei, M.R., Marzban, A., Alrashed, A.A., Ahmadi, G.R. and Nguyen, T.K., 2017. Heat transfer improvement of water/single-wall carbon nanotubes (SWCNT) nanofluid in a novel design of a truncated double-layered microchannel heat sink. International Journal of Heat and Mass Transfer, 113, pp.780-795.

[49] Malvandi, A., Safaei, M.R., Kaffash, M.H. and Ganji, D.D., 2015. MHD mixed convection in a vertical annulus filled with A12O3-water nanofluid considering nanoparticle migration. Journal of Magnetism and Magnetic Materials, 382, pp.296-306.

[50] Togun, H., Safaei, M.R., Sadri, R., Kazi, S.N., Badarudin, A., Hooman, K. and Sadeghinezhad, E., 2014. Numerical simulation of laminar to turbulent nanofluid flow and heat transfer over a backward-facing step. Applied Mathematics and Computation, 239, pp.153-170.

[51] Goshayeshi, H.R., Goodarzi, M., Safaei, M.R. and Dahari, M., 2016. Experimental study on the effect of inclination angle on heat transfer enhancement of a ferrofluid in a closed loop oscillating heat pipe under magnetic field. Experimental Thermal and Fluid Science, 74, pp.265270.

[52] Akbari, O.A., Safaei, M.R., Goodarzi, M., Akbar, N.S., Zarringhalam, M., Shabani, G.A.S. and Dahari, M., 2016. A modified two-phase mixture model of nanofluid flow and heat transfer in a 3-D curved microtube. Advanced Powder Technology, 27(5), pp.2175-2185.

[53] Goshayeshi, H.R., Safaei, M.R., Goodarzi, M. and Dahari, M., 2016. Particle size and type effects on heat transfer enhancement of Ferro-nanofluids in a pulsating heat pipe. Powder Technology, 301, pp.1218-1226.

[54] Heydari, A., Akbari, O.A., Safaei, M.R., Derakhshani, M., Alrashed, A.A., Mashayekhi, R., Shabani, G.A.S., Zarringhalam, M. and Nguyen, T.K., 2018. The effect of attack angle of triangular ribs on heat transfer of nanofluids in a microchannel. Journal of Thermal Analysis and Calorimetry, 131(3), pp.2893-2912. 
[55] Khodabandeh, E., Safaei, M.R., Akbari, S., Akbari, O.A. and Alrashed, A.A., 2018. Application of nanofluid to improve the thermal performance of horizontal spiral coil utilized in solar ponds: geometric study. Renewable Energy, 122, pp.1-16.

[56] Togun, H., Ahmadi, G., Abdulrazzaq, T., Shkarah, A.J., Kazi, S.N., Badarudin, A. and Safaei, M.R., 2015. Thermal performance of nanofluid in ducts with double forward-facing steps. Journal of the Taiwan Institute of Chemical Engineers, 47, pp.28-42.

[57] Alrashed, A.A., Gharibdousti, M.S., Goodarzi, M., de Oliveira, L.R., Safaei, M.R. and Bandarra Filho, E.P., 2018. Effects on thermophysical properties of carbon based nanofluids: Experimental data, modelling using regression, ANFIS and ANN. International Journal of Heat and Mass Transfer, 125, pp.920-932.

[58] Maleki, H., Safaei, M.R., Alrashed, A.A. and Kasaeian, A., 2019. Flow and heat transfer in non-Newtonian nanofluids over porous surfaces. Journal of Thermal Analysis and Calorimetry, 135(3), pp.1655-1666.

[59] Abbassi, M.A., Safaei, M.R., Djebali, R., Guedri, K., Zeghmati, B. and Alrashed, A.A., 2018. LBM simulation of free convection in a nanofluid filled incinerator containing a hot block. International Journal of Mechanical Sciences, 144, pp.172-185.

[60] Maleki, H., Safaei, M.R., Togun, H. and Dahari, M., 2019. Heat transfer and fluid flow of pseudo-plastic nanofluid over a moving permeable plate with viscous dissipation and heat absorption/generation. Journal of Thermal Analysis and Calorimetry, 135(3), pp.1643-1654.

[61] Bahiraei, M., Salmi, H.K. and Safaei, M.R., 2019. Effect of employing a new biological nanofluid containing functionalized graphene nanoplatelets on thermal and hydraulic characteristics of a spiral heat exchanger. Energy conversion and management, 180, pp.72-82.

[62] Aboulhasan Alavi, S.M., Safaei, M.R., Mahian, O., Goodarzi, M., Yarmand, H., Dahari, M. and Wongwises, S., 2015. A hybrid finite-element/finite-difference scheme for solving the 3-D energy equation in transient nonisothermal fluid flow over a staggered tube bank. Numerical Heat Transfer, Part B: Fundamentals, 68(2), pp.169-183.

[63] Shadlaghani, A., Farzaneh, M., Shahabadi, M., Tavakoli, M.R., Safaei, M.R. and Mazinani, I., 2019. Numerical investigation of serrated fins on natural convection from concentric and eccentric annuli with different cross sections. Journal of Thermal Analysis and Calorimetry, 135(2), pp.1429-1442. 
[64] Sarafraz, M.M., Safaei, M.R., Goodarzi, M., Yang, B. and Arjomandi, M., 2019. Heat transfer analysis of Ga-In-Sn in a compact heat exchanger equipped with straight micro-passages. International Journal of Heat and Mass Transfer, 139, pp.675-684.

[65] Abdul Hakeem, A.K., Ragupathi, P., Saranya, S. and Ganga, B., 2019. Three Dimensional Non-linear Radiative Nanofluid Flow over a Riga Plate. Journal of Applied and Computational Mechanics.

[66] RAWAT, S.K., Upreti, H. and Kumar, M., 2020. Comparative Study of Mixed Convective MHD Cu-Water Nanofluid Flow over a Cone and Wedge using Modified Buongiorno's Model in Presence of Thermal Radiation and Chemical Reaction via Cattaneo-Christov Double Diffusion Model. Journal of Applied and Computational Mechanics.

[67] Akinshilo, A.T., Ilegbusi, A., Ali, H.M. and Surajo, A.J., 2020. Heat Transfer Analysis of Nanofluid Flow with Porous Medium through Jeffery Hamel Diverging/Converging Channel. Journal of Applied and Computational Mechanics, 6(3), pp.433-444.

[68] Patra, A., Nayak, M.K. and Misra, A., 2020. Effects of Non-uniform Suction, Heat Generation/Absorption and Chemical Reaction with Activation Energy on MHD Falkner-Skan Flow of Tangent Hyperbolic Nanofluid over a Stretching/Shrinking Eedge. Journal Archive, Volume 6, Issue 3, Summer 2020, Pages 640-652.

[69] Yadav, D., 2020. The Density-Driven Nanofluid Convection in an Anisotropic Porous Medium Layer with Rotation and Variable Gravity Field: A Numerical Investigation. Journal of Applied and Computational Mechanics, 6(3), pp.699-712.

[70] Kumar, B. and Srinivas, S., 2020. Unsteady Hydromagnetic Flow of Eyring-Powell Nanofluid over an Inclined Permeable Stretching Sheet with Joule Heating and Thermal Radiation. Journal of Applied and Computational Mechanics, 6(2), pp.259-270.

[71] Ahmed, N., Ali Shah, N., Ahmad, B., Shah, S.I., Ulhaq, S. and Gorji, M.R., 2019. Transient MHD convective flow of fractional nanofluid between vertical plates. Journal of Applied and Computational Mechanics, 5(4), pp.592-602.

[72] Dogonchi, A.S., Chamkha, A.J., Seyyedi, S.M., Hashemi-Tilehnoee, M. and Ganji, D.D., 2019. Viscous dissipation impact on free convection flow of $\mathrm{Cu}$-water nanofluid in a circular enclosure with porosity considering internal heat source. Journal of Applied and Computational Mechanics, 5(4), pp.717-726. 
[73] Sobamowo, G., 2019. Free convection flow and heat transfer of nanofluids of different shapes of nano-sized particles over a vertical plate at low and high Prandtl numbers. Journal of Applied and Computational Mechanics, 5(1), pp.13-39.

[74] Mohamed, K., Mohamed Rafik, S., Rabah, B.O.U.R.E.N.A.N.E., Rashidi, M.M. and Ammar, H.A.I.A.H.E.M., 2018. Heat transfer in hydro-magnetic nano-fluid flow between non-parallel plates using DTM. Journal of Applied and Computational Mechanics, 4(4), pp.352-364.

[75] Rajabzadeh, B., Najafabadi, M.H. and Karimipour, A., 2019. Effects of new methods of porosity arrangement on forced convection in a variable BDPM using numerical simulation. International Journal of Thermal Sciences, 146, p.106004.

[76] Tian, Z., Arasteh, H., Parsian, A., Karimipour, A., Safaei, M.R. and Nguyen, T.K., 2019. Estimate the shear rate $\&$ apparent viscosity of multi-phased non-Newtonian hybrid nanofluids via new developed Support Vector Machine method coupled with sensitivity analysis. Physica A: Statistical Mechanics and its Applications, 535, p.122456.

[77] Liu, W.I., Malekahmadi, O., Bagherzadeh, S.A., Ghashang, M., Karimipour, A., Hasani, S., Tlili, I. and Goodarzi, M., 2019. A novel comprehensive experimental study concerned graphene oxide nanoparticles dispersed in water: Synthesise, characterisation, thermal conductivity measurement and present a new approach of RLSF neural network. International Communications in Heat and Mass Transfer, 109, p.104333.

[78] Mozaffari, M., Karimipour, A. and D’Orazio, A., 2019. Increase lattice Boltzmann method ability to simulate slip flow regimes with dispersed CNTs nanoadditives inside. Journal of Thermal Analysis and Calorimetry, 137(1), pp.229-243.

[79] Karimipour, A., D'Orazio, A. and Goodarzi, M., 2018. Develop the lattice Boltzmann method to simulate the slip velocity and temperature domain of buoyancy forces of FMWCNT nanoparticles in water through a micro flow imposed to the specified heat flux. Physica A: Statistical Mechanics and Its Applications, 509, pp.729-745. 